Research Article

\title{
Transmitting Characteristics of Seismic Motion in Super-Deep Overburden Layer Ground
}

\author{
Long Wang $\mathbb{D}^{1,},{ }^{1,2}$ Zheng-quan Yang $\mathbb{D}^{1,2}$ Jian-ming Zhao $\mathbb{D}^{1,2}$ Xiao-sheng Liu $\mathbb{D}^{1,2}$ \\ and Yan-feng Wen $\mathbb{D D}^{1,2}$ \\ ${ }^{1}$ State Key Laboratory of Simulation and Regulation of Water Cycle in River Basin, Beijing 100038, China \\ ${ }^{2}$ Department of Geotechnical Engineering, China Institute of Water Resources and Hydropower Research, Beijing 100048, China
}

Correspondence should be addressed to Zheng-quan Yang; yangzhq@iwhr.com

Received 12 August 2020; Revised 5 February 2021; Accepted 10 February 2021; Published 28 February 2021

Academic Editor: Songye Zhu

Copyright (C) 2021 Long Wang et al. This is an open access article distributed under the Creative Commons Attribution License, which permits unrestricted use, distribution, and reproduction in any medium, provided the original work is properly cited.

\begin{abstract}
Dynamic response characteristics and antiseismic performance of the structures which were constructed on the super-deep overburden layer are affected obviously by the seismic motion characteristics of the super-deep overburden layer foundation. In this paper, the seismic motion characteristics of horizontally stratified super-deep overburdenIn this paper, the seismic motion characteristics of horizontally stratified super-deep overburden based on the research results of on-site in situ tests and indoor material property tests, the horizontal shear layer method that can consider the nonlinear characteristics of dynamic soil deformation and the characteristics of seismic wave propagation in the soil is used to study the characteristics of ground motions of super-deep and thick overburden level of an earth-rock dam in China. The influence law of input ground motion characteristics and input ground motion position on seismic response analysis results of overburden ground is studied. Taking the uniform overburden layer model as an example, the coupling influence analysis of soil layer thickness and shear velocity on ground motion response are carried out, and the coupling influence law is proposed. The study shows that the seismic motion propagating characteristics of the earthquake in super-deep overburden layer is involved, inputting location of the seismic motion affects the results of ground seismic response greatly; super-deep overburden layer thickness and the soil shear wave velocity on influence law of ground motion characteristics have coupling. When the shear wave velocity of the soil layer is constant, the surface acceleration response has an inflection point with the change of the soil layer thickness; when the thickness of overburden is constant, the surface acceleration response also has an inflection point with the change of shear wave velocity of the soil layer; these inflexion values are influenced by both soil thickness and shear wave velocity.
\end{abstract}

\section{Introduction}

With the extensive and in-depth development of the global water conservancy and hydropower industry, the problem of strong earthquakes and deep overburden foundations has become a double challenge for hydropower project construction, and it is difficult to evade, becoming a controlling factor for the successful construction of many projects [1]. The main structure of the CCS (Coca Codo Sinclair) hydro project in Ecuador has been built on a super-deep overburden over $200 \mathrm{~m}$ thickness. There are several active volcanoes around the project site, and the intensity of the maximum credible earthquake is IX degree. The asphalt concrete core dam of Xiabandi hydro-junction (in Xinjiang province of China) was constructed on the deep overburden layer which has a maximum depth of $150 \mathrm{~m}$, and the basic earthquake intensity of the dam site is VIII degree. The Yele earth-rock fill dam had been constructed in the Sichuan province of China, and the maximum depth of the dam foundation overburden layer is over $400 \mathrm{~m}$. The seismic fortification intensity of the dam is IX degree, and the maximum horizontal acceleration of the bedrock was determined as 441.5 gals according to the results of region earthquake hazard analysis.

The ground motion characteristics of the site with deep overburden in the river valley have an essential influence on the dynamic response characteristics of the upper earth-rock dam, gate dam, and diversion structure [1], because the 
characteristics of earthquake inputting from the bedrock down overburden layer are changed greatly by the deep overburden layer. The analyzed object is the structural system that contains the structure and its near-field foundation in the dynamic analysis of hydraulic structure on deep overburden layer normally, and the size of the structure near-field foundation is limited. Because the response of local area in the structure should be paid more attention, together with the demand that the numerical element size should be coordinated with the wavelength, the scale of the structure foundation should not be too large considering the difficulty and working load of calculation. Especially when the thickness of the overburden layer in the valley is relatively large relative to the height of the structure, it is obviously inappropriate to take the soil layer within the thickness of the entire overburden layer as the near-field foundation of the calculation model. It is advisable to cutoff the foundation of the overburden layer and take only a cover layer of a certain thickness is used as the calculated near-field foundation. The seismic motion of this truncated boundary is different from the seismic motion of the bedrock surface under the soil layer. The ground seismic response analysis of the deep overburden layer should be conducted to study the influence law of overburden layer on the characteristics of the seismic motion inputted from bedrock. The seismic motion characteristics of calculation model boundary should be determined to provide seismic motion characteristic parameters for the dynamic analysis of the structure and foundation system on the deep overburden layer [2]. Besides, the application of the pseudostatic method in hydraulic structure design should be in the premise of that determining the seismic motion characteristic parameters of calculation model boundary [3].

Wang et al. [4] discussed the influence of boundary interception range on acceleration response of dam body when wave method is adopted. The results show that the acceleration response of the dam is obviously higher than that of the fluctuation method, and the vertical seismic action is more significant. The sensitivity of the fluctuation method is obviously lower than that of the vertical seismic input when the horizontal ground motion is input. Ting and Shao [5] carried out the sensitivity analysis of the thickness of overburden, the peak value of input seismic wave, and the thickness of soft soil layer in the overburden. It is concluded that the thickness of overburden, the peak value of input acceleration, and the thickness of soft soil layer are positively correlated with the attenuation of the magnification of the base surface, and the basic law of the acceleration magnification of overburden with elevation is attenuation firstly and then amplification. When there is a weak soil layer, the secondary attenuation of dynamic reaction will occur in the soil layer due to its filtering isolation. Han et al. [6] compared and analyzed the dynamic response of the lower dam for the seismic action of pulse type and nonpulse type. The results show that the impulse ground motion has a certain influence on the acceleration response of the high earth-rock dam on the deep overburden. It makes the dam body deform greatly in a very short time, which is not conducive to the dam safety. Taking into account the change of soil thickness, the change of bedrock topography, and the influence of new structure, Yang et al. [7] studied the influence of the change of overburden structure on-site ground motion and concluded that the overburden has a significant influence on the amplitude of site ground motion. Zhu et al. [8] and Wang et al. [9] believe that the dynamic response of the dam on the deep overburden is a single relationship with the thickness of the overburden and the input of ground motion, and there is no superposition effect.

There is an earth-rock fill dam whose main body structure is constructed on the valley super-deep overburden layer in China, and it is the first case in global dam engineering fields for that the maximum thickness of this superdeep overburden layer is more than $500 \mathrm{~m}$ [10]. The dam is constructed on a high earthquake-intensity site in which the horizontal peak acceleration of bedrock is over 500 gal with the exceeding probability of 2.0 in 100 years. Not only the thickness of the overburden layer foundation is large but also the structure of soil layer is complicated that can be understood in the following description, and the difficulty of foundation treatment is serious. Taking this super-deep overburden layer as the basic research object, seismic motion transmitting characteristics of the overburden layer foundation have been studied deeply in the paper. The influence rules of the seismic motion characteristics of earthquake inputting from bedrock and the inputting position of the earthquake in the ground seismic response analysis on the seismic motion transmitting characteristics of soil layer have been analyzed too. Moreover, series of ground models with thickness and shear wave velocity of soil layer are different and are established based on the former real super-deep overburden layer model. The coupling influencing analysis of soil layer thickness and shear velocity on the seismic motion characteristics of ground is performed, and the coupling influencing rule is proposed in the end.

\section{Analysis Methods}

2.1. Summary of Ground Seismic Analysis Methods. The methods of determining ground seismic motion parameters can be classified into two types generally: one is the specification method, which is summarized based on the engineering experience, and it can be used simply and conveniently by engineers; the other is the ground seismic analysis method, in which theoretical models and calculating process are more complete, and the calculating model should be established based on the real site condition firstly. There are two types of ground seismic analysis methods, the back analysis method and the forward analysis method. The back analysis method can obtain the seismic motion parameters of the soil layer in any depth underground surface when the natural earthquake of soil layer ground free surface has been recorded and can obtain the seismic motion parameters of bedrock surface too. The forward analysis method can study the seismic motion characteristics of soil layer in any height up bedrock surface when the site earthquake of horizontal bedrock free surface has been defined by the region earthquake hazard analysis, and the seismic motion characteristics of ground surface can be obtained too. 
Based on the simplification mode of the soil layer structure, the ground seismic analysis methods can be distinguished as horizontal layer shearing method, centralized mass system method, numerical analysis method (such as finite element method), and so on. Meanwhile, they also can be distinguished as time-domain analysis method and frequency-domain analysis method based on the solving method. The horizontal layer shearing method and the centralized mass system method are suitable for the ground seismic analysis of horizontally stratified soil layer under the shear horizontal waves, and they can be solved using a linear method or equivalent nonlinear method [11-13]. Using the finite element method and the other numerical analysis methods, we obtain the ground seismic analysis of soil layers in which geometry shapes are arbitrary under multidimensional earthquakes, and they can be solved using the linear method, equivalent linearization method, and real nonlinear method [14, 15].

For the horizontally stratified super-deep overburden soil layer ground in which thickness is over $500 \mathrm{~m}$, it is reasonable and feasible that the ground seismic analysis of soil layer is carried out using the horizontal layer shearing method which can consider the superposition effect of the incident wave and reflected wave and the influence of superdeep soil layer on the vibration characteristics of bedrock surface under soil layer for the following reasons. Firstly, because the thickness of soil layer is large, vibration characteristics of the soil layer are influenced greatly by the superposition effect of the incident wave and reflected wave when the earthquake transmits in the ground; secondly, the real vibration characteristics of bedrock surface under soil layer are different greatly from the vibration characteristics of free bedrock surface with no soil on it (it is the site earthquake from the region earthquake hazard analysis) because the thickness of soil layer is too large; lastly, the seismic motion, which affects the vibration characteristics of super-deep overburden layer ground and the hydraulic structures on it greatly, is the horizontal shearing wave which transmits vertically from the deep crust. In this paper, the horizontal layer shearing method is the basic analysis method for ground seismic analysis to study the influencing rule of super-deep overburden layer on the seismic motion characteristics of the earthquake from bedrock under soil layer. The vibration acceleration response characteristics of soil layer are the reference object of the seismic motion characteristics analysis of overburden layer ground, which contains the acceleration amplitude and spectrum characteristics of the vibration.

\subsection{Horizontal Layer Shearing Method Based on Wave Theory.} For the horizontally stratified soil layer ground, the transmitting progress of horizontal shear wave inputting from bedrock under soil layer can be represented by the schematic diagram in Figure 1. As Figure 1 shows, the site (including the semi-infinite horizontal bedrock under the soil layer) is divided into $N$ horizontal layers, and the layers' number is $1-N$ from the ground surface to the half-space bedrock. The earthquake produced in deep crust transmits vertically into the overburden layer ground foundation through the halfspace bedrock and reflects back to soil layer ground and deep bedrock when it transmits to ground surface.

The $u-x$ whole coordinate system of a two-dimensional plane for a ground model is established, as shown in Figure 1 , and the position coordinate of particles in the vertical direction is represented as $x$ and the horizontal dynamic displacement of particles vibration is represented as $u$. Assuming soil is the material that deforms in the viscoelastic model, the relationship of $u$ (particles' horizontal vibration displacement in a soil layer) with $x$ (particles' vertical position coordinate) and $t$ (time) is represented by the wave equation as equation (1) when the horizontal shear wave from bedrock underground transmits vertically in the soil layer.

$$
\rho \frac{\partial^{2} u}{\partial t^{2}}=G \frac{\partial^{2} u}{\partial x^{2}}+\eta \frac{\partial^{3} u}{\partial x^{2} \partial t},
$$

where $\rho, G$, and $\eta$ are the density, shearing modulus, and viscosity coefficient of soil, and the viscosity coefficient of soil can be obtained by the equation $\eta=2 G \lambda / \omega$ ( $\lambda$ is the damping ratio of soil and $\omega$ is the angular vibration frequency).

An irregular earthquake in time domain can be transformed into a wave group of some simple harmonic waves in frequency domain in which vibration amplitude is different. The simple harmonics with a frequency $\omega$ causes the vibrating displacement of the particle in the horizontal direction can be expressed as the following equation:

$$
u(x, t)=U(x) \cdot e^{i \omega t},
$$

where $U(x)$ is the amplitude of particle vibration. By equations (1) and (2), the partial differential equation, as shown in equation (3) can be obtained,

$$
(G+i \omega \eta) \frac{\partial^{2} U}{\partial x^{2}}=\rho \omega^{2} U,
$$

where $U(x)$ is represented as equation (4) by solving the partial differential equation above,

$$
U(x)=E e^{i k x}+F e^{-i k x} .
$$

In equation (4), $k$ is the complex wave number; it satisfies the following formula:

$$
k^{2}=\frac{\rho \omega^{2}}{G+i \omega \eta}=\frac{\rho \omega^{2}}{G^{*}},
$$

where $G^{*}$ is the complex shear modulus.

In the general case, the values of soil shearing modulus $(G)$ and damping ratio $(\lambda)$ are correlative with the vibration frequency of soil layer $(\omega)$. Still, they are nearly constant in the frequency domains that engineers are interested in it. So, the complex shear modulus $\left(G^{*}\right)$ can be represented as the following equation:

$$
G^{*}=G+i \omega \eta=G(1+2 i \lambda) .
$$




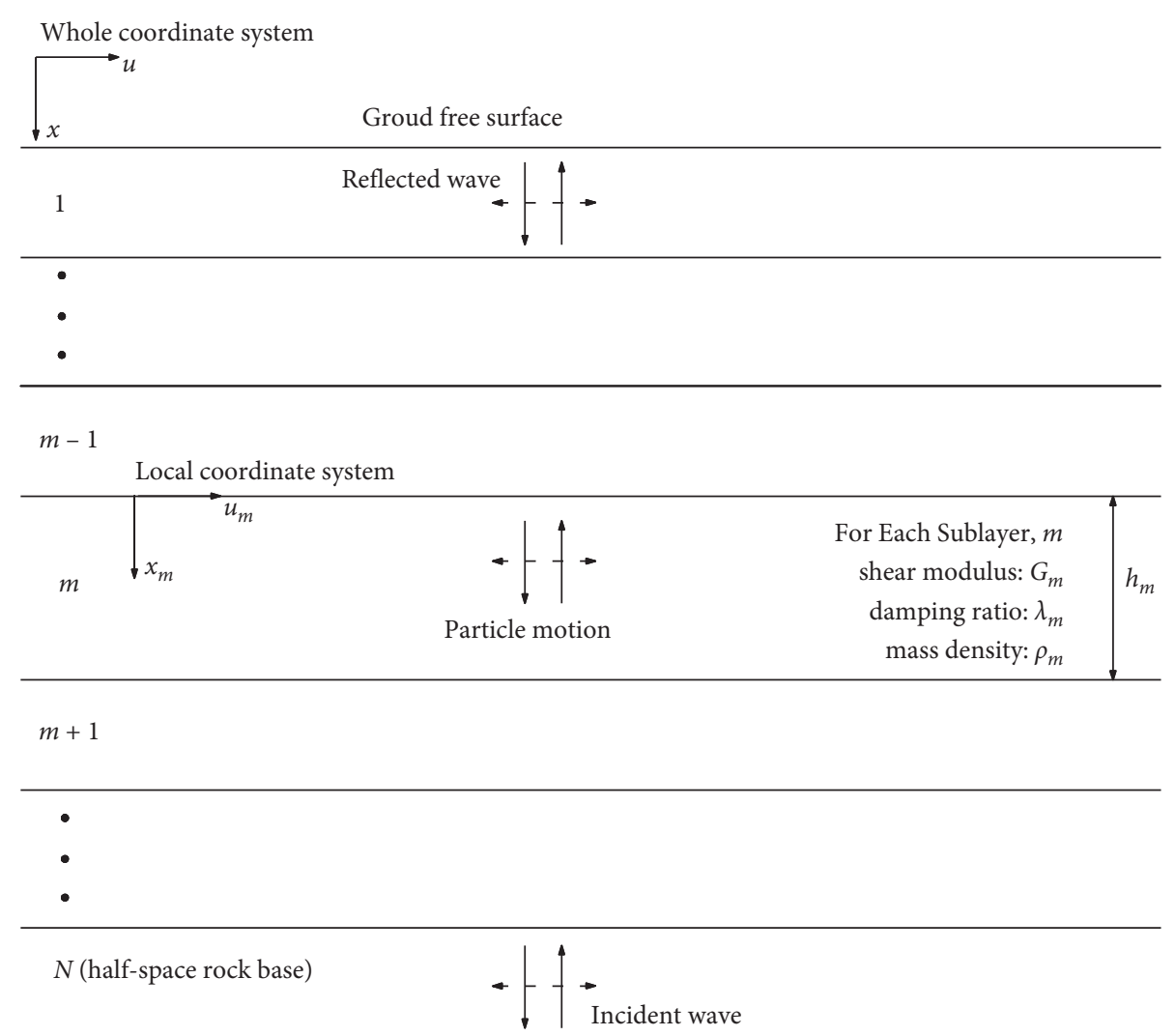

Figure 1: Two-dimensional diagram of oblique incidence of plane $P$ wave.

By equations (2)-(6), the particles' horizontal vibrating displacement is obtained as the following equation:

$$
u(x, t)=E e^{i(k x+\omega t)}+F e^{-i(k x-\omega t)} .
$$

Note that in equation (7), particles' horizontal vibrating state of soil layer $u(x, t)$ can be represented by two contents: the first one is $u_{1}=E e^{i(k x+\omega t)}$; as there is increasing of time, in order to obtain the same $u_{1}$, the $x$ needs to be a new value smaller than former, so the expression represents the exercising results of the incident wave which transmits vertically in the negative direction along $x$ coordinate axis; the other one is $u_{2}=F e^{-i(k x-\omega t)}$; similarly as before, the expression represents the exercising results of the reflected wave which transmits vertically in the positive direction along the $x$ coordinate axis. The levels of vibration amplitude of incident wave and reflected wave are defined by $E$ and $F$ which are called as wave amplitude coefficients.

For any soil layer of the ground (the soil layer number is " $m$ "), the local coordinate system $u_{m}-x_{m}$ is introduced, and the vibration displacement of soil layer top surface and bottom surface can be represented respectively as the following equations:

$$
\begin{gathered}
u_{m}\left(x_{m}=0\right)=\left(E_{m}+F_{m}\right) e^{i \omega t}, \\
u_{m}\left(x_{m}=h_{m}\right)=\left(E_{m} e^{i k_{m} h_{m}}+F_{m} e^{-i k_{m} h_{m}}\right) e^{i \omega t} .
\end{gathered}
$$

The shear stress of any horizontal plane in the soil layer is represented as the following equation:

$$
\tau(x, t)=G \frac{\partial u}{\partial x}+\eta \frac{\partial u}{\partial x \partial t}=G^{*} \frac{\partial u}{\partial x} .
$$

Considering equation (7), equation (9) can be represented as equation (10); furthermore,

$$
\tau(x, t)=i k G^{*}\left(E e^{i k x}-F e^{-i k x}\right) e^{i \omega t}
$$

So, the shear stress of soil layer top surface and bottom surface are represented, respectively, as the following equation:

$$
\begin{gathered}
\tau_{m}\left(x_{m}=0\right)=i k_{m} G_{m}^{*}\left(E_{m}-F_{m}\right) e^{i \omega t} \\
\tau_{m}\left(x_{m}=h_{m}\right)=i k_{m} G_{m}^{*}\left(E_{m} e^{i k_{m} h_{m}}-F_{m} e^{-i k_{m} h_{m}}\right) e^{i \omega t} .
\end{gathered}
$$

The stress and vibration displacement on any interface of soil layers are continuous. Based on equations (8) and (11), equations (12) and (13) are obtained,

$$
\begin{aligned}
& E_{m+1}+F_{m+1}=E_{m} e^{i k_{m} h_{m}}+F_{m} e^{-i k_{m} h_{m}}, \\
& E_{m+1}-F_{m+1}=\frac{k_{m} G_{m}^{*}}{k_{m+1} G_{m+1}^{*}}\left(E_{m} e^{i k_{m} h_{m}}-F_{m} e^{-i k_{m} h_{m}}\right) .
\end{aligned}
$$

Solving the coupled equations of (12) and (13), the relationships of $E_{m+1}$ with $E_{m}$ and $F_{m+1}$ with $F_{m}$ can be represented as equations (14) and (15), 


$$
\begin{aligned}
& E_{m+1}=\frac{1}{2} E_{m}\left(1+\alpha_{m}\right) e^{i k_{m} h_{m}}+\frac{1}{2} F_{m}\left(1-\alpha_{m}\right) e^{-i k_{m} h_{m}}, \\
& F_{m+1}=\frac{1}{2} E_{m}\left(1-\alpha_{m}\right) e^{i k_{m} h_{m}}+\frac{1}{2} F_{m}\left(1+\alpha_{m}\right) e^{-i k_{m} h_{m}} .
\end{aligned}
$$

In equations (14) and (15), $\alpha_{m}$ is the complex wave impedance ratio, and it can be represented as the following equation:

$$
\alpha_{m}=\frac{k_{m} G_{m}^{*}}{k_{m+1} G_{m+1}^{*}}=\left(\frac{\rho_{m} G_{m}^{*}}{\rho_{m+1} G_{m+1}^{*}}\right)^{1 / 2} .
$$

The shear stress in the surface of ground is 0 , so the result of $E_{1}=F_{1}$ is got based on equation (10), and the recursive relations of $E_{m}$ and $F_{m}$ of any soil layer in which soil layer number is $m$ with $E_{1}$ (or $F_{1}$ ) are represented as equations (17a) and (17b). Based on equations (17a) and (17b), the wave amplitude coefficients of incident wave and reflected wave of all soil layers could be obtained recursively if the wave amplitude coefficient of incident wave or reflected wave of any soil layer is known.

$$
\begin{aligned}
& E_{m}=e_{m}(\omega) E_{1}, \\
& F_{m}=f_{m}(\omega) E_{1},
\end{aligned}
$$

where in equation (17), $e_{m}(\omega)$ and $f_{m}(\omega)$ are the quantities associated with the natural vibration angular frequency of the harmonic wave, and they are obtained based on the structure characteristics parameters of ground model.

The transmitting progress of earthquake waves that contain incident waves and reflected waves is shown in Figure 2. Because the incident wave cannot be influenced by the upper overburden layer on the surface of bedrock, the vibration amplitude of incident wave $\left(E_{n}\right)$ is half of it on rock outcrop $\left(2 E_{n}\right)$. The vibration progress of rock outcrop should be considered same as the site earthquake, which is the vibration acceleration time history of horizontal bedrock free surface, and the site earthquake can be obtained by the region earthquake hazard analysis. The vibration amplitudes of incident wave $\left(E_{m}\right)$ and reflected wave $\left(F_{m}\right)$ of any soil layer " $m$ " in the ground can be obtained recursively by the recursive relations (as equation (17)) when the amplitude of incident wave on the surface of bedrock under overburden layer $\left(E_{n}\right)$ is defined based on the earthquake time history which is the result of region earthquake hazard analysis for the study site.

Furthermore, the horizontal vibration acceleration and shear stress of any soil layer in the ground are represented as equations (18) and (19), and the other characteristic quantities can be obtained recursively too.

$$
\begin{gathered}
\ddot{u}(x, t)=\frac{\partial^{2} u}{\partial t^{2}}=-\omega^{2}\left(E e^{i(k x+\omega t)}+F e^{-i(k x-\omega t)}\right), \\
\gamma=\frac{\partial u}{\partial x}=i k\left(E e^{i(k x+\omega t)}-F e^{-i(k x-\omega t)}\right) .
\end{gathered}
$$

\section{Example Analysis for Seismic Motion Characteristics of Super-Deep Overburden Layer}

One reservoir will be constructed in China, and the waterretaining structure is an earth-rock fill dam whose main body is constructed on the super-deep overburden layer in a wide valley. The thickness of valley overburden layer is large in the whole range of the dam sites, and the thickness of most ground regions around the dam is more than $500 \mathrm{~m}$. Combining with many drilling data in the dam site area, we can see that soil layers of overburden layer foundation are horizontally stratified well and the thickness of soil layers along horizontal direction changes little in the range of project. The valley super-deep overburden layer foundation is constituted by seven main soil layers; those soil layers from down to up are layer (1), moraine and glacial relics stacking crushed-rock layer; layer (2), alluvial-pluvial and stacking sand layer containing crush (or pebble); layer (3)-1, fluviallacustrine deposit sand layer containing gravel; layer (3)-2, fluvial-lacustrine deposit silty clay layer; layer (3)-3, fluviallacustrine deposit sand layer containing gravel; layer (4), modern alluvial deposit sand gravel stratum layer.

In the engineering design stage, a large number of on-site surveys were carried out, and the site soils have been transported to the laboratory used to do dynamic characteristic tests. All those achievements of site geotechnical investigation and laboratory material tests can be the basic data of ground seismic analysis [10].

3.1. Model of Ground Seismic Analysis. The soil layer of the overburden layer in the dam site area shows a good horizontal stratification, and the thickness of the soil layer along the horizontal river direction (the most dangerous direction of ground motion) changes little. Because the thickness of the foundation soil layer is large, the fluctuation effects are obvious when the earthquake transmits in the soil layer ground, and the vibration characteristics of bedrock surface are influenced obviously by the super-deep overburden soil layer on the bedrock. According to these actual conditions, considering the wave effect of horizontal seismic waves propagating on the ground, it is reasonable and feasible to use the horizontal layer shear method for ground motion analysis. Because the soil layers are horizontally stratified well in the whole range of ground, the ground seismic analysis model can be established based on the data of one typical drilling, which reveals that the thickness of soil layer is bigger than others. The typical drilling reveals that the thickness of soil layer is $566.9 \mathrm{~m}$. Soil layer structure and soil features of the ground are shown as the above description and the drilling structure diagram (Figure 3), and the field cross-hole wave velocity tests have been performed to definite the shear wave velocity of soil layers further more (Figure 3).

According to the distribution of the soil layer and the shear wave speed, it is necessary to avoid the calculation model from being too large while ensuring the calculation accuracy. The soil layer thickness of the site analysis model is 


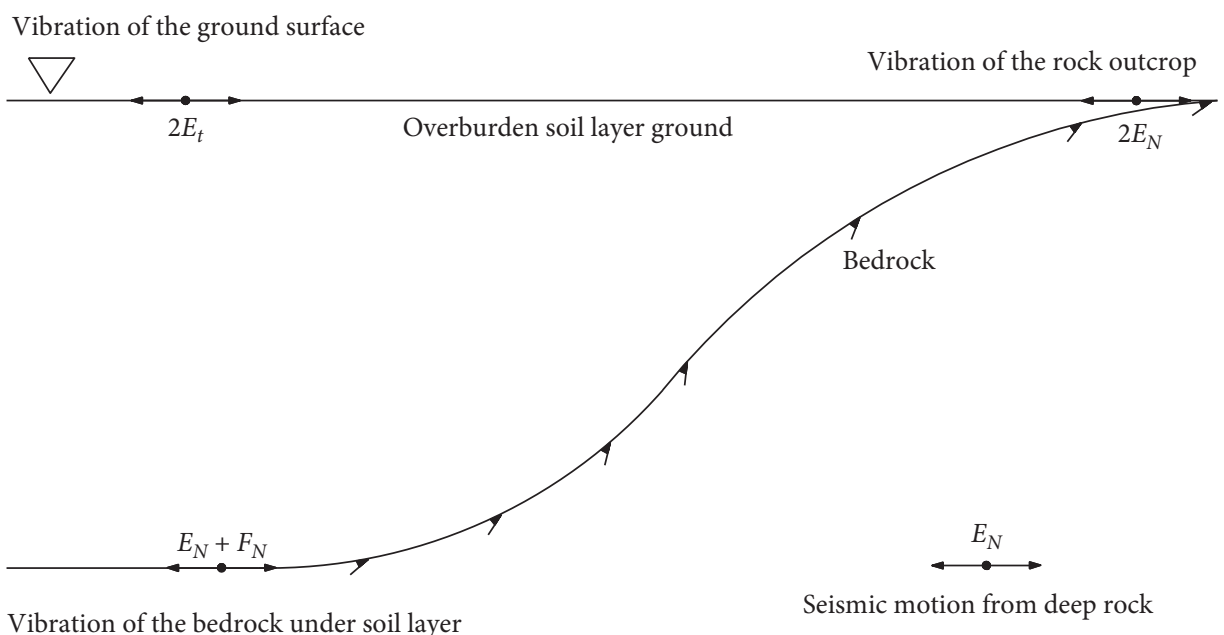

FIGURE 2: The relationship schematic diagram of soil layer's vibration and bedrock's vibration in the ground system.

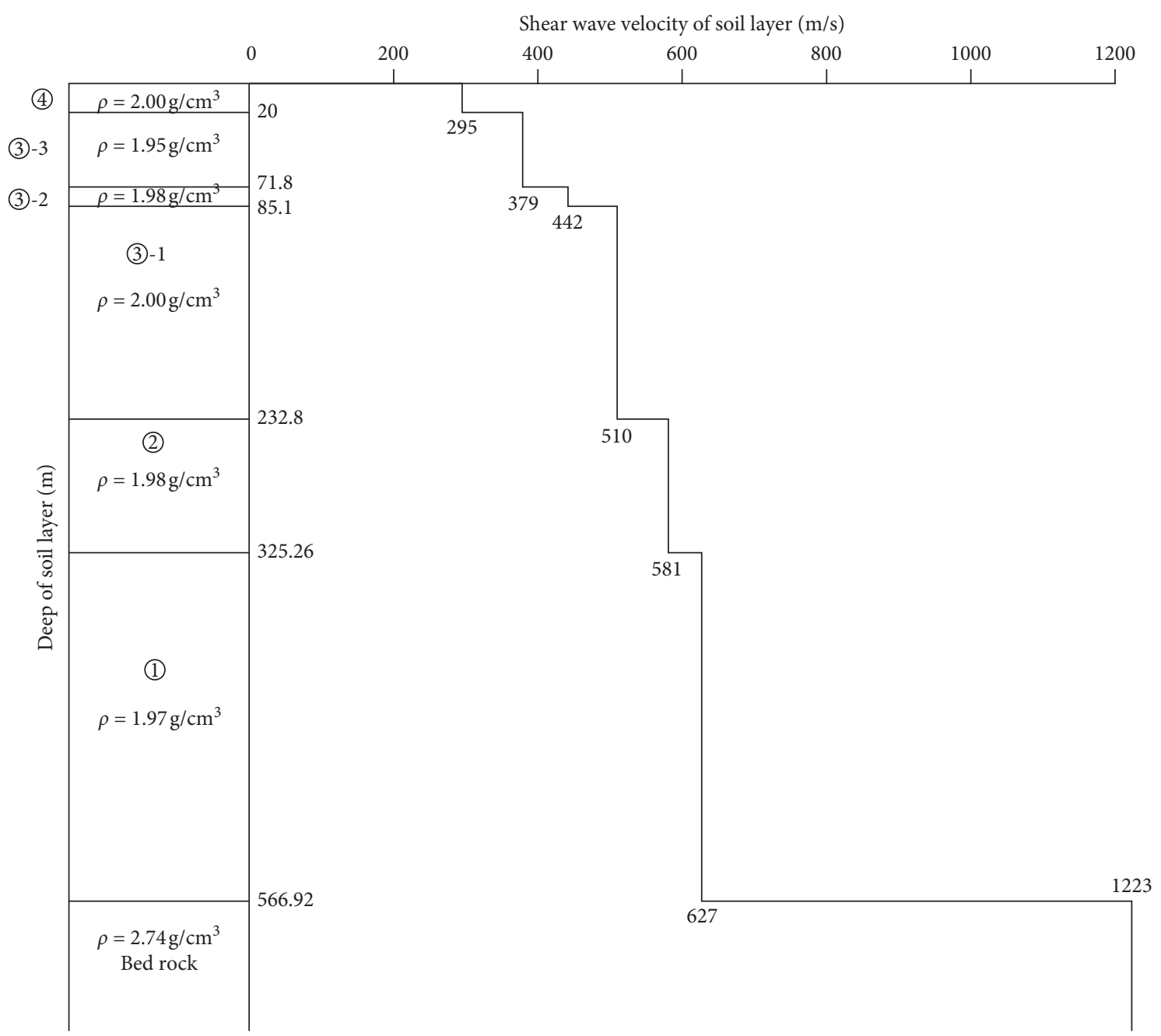

Figure 3: The soil layer structure of ground based on structure diagram of the typical drilling.

divided to ensure that the maximum soil layer thickness is not greater than $1 / 6$ of the shear wave wavelength $[11,12]$. Simultaneously, the component of the input ground motion of the bedrock has a significant impact on the site and the structure on the foundation is the part with a frequency lesser than $10 \mathrm{~Hz}$. Accordingly, the soil layer of the site in Figure 3 is divided into 77 sublayers, including the horizontal bedrock layer with a semi-infinite space at the bottom. 
Among them, the thickness of each sublayer of the soil layer (layer (1), layer (2), and layer (3)-1) with wave speed greater than $500 \mathrm{~m} / \mathrm{s}$ is $8 \mathrm{~m}$, and the wave speed lesser than $500 \mathrm{~m} / \mathrm{s}$ corresponds to $1 / 6$ of the minimum wavelength of $50 \mathrm{~m}$ which is $8.33 \mathrm{~m}$. The thickness of each sublayer of the soil layer (layer (3)-2, layer (3)-3, and layer (4)) with a wave velocity of $295-500 \mathrm{~m} / \mathrm{s}$ is $5 \mathrm{~m}$, which is basically the same as $1 / 6(4.91 \mathrm{~m})$ of the minimum wavelength of $29.5 \mathrm{~m}$ corresponding to the wave velocity of $295 \mathrm{~m} / \mathrm{s}$.

\subsection{Dynamic Characteristic Parameters of Soil in Ground} Seismic Analysis. Soil of overburden layer is the material that deforms in visco-elastic mode, and the equivalent nonlinear visco-elastic dynamic model improved by Zhujiang Shen has been used to reflect the nonlinear characteristics of soil dynamic stress-strain relationship under the seismic loading [16].

The normal equivalent nonlinear visco-elastic dynamic model had been improved by Zhu-jiang Shen, and the improved model can be used more conveniently than before $[11,16]$. In the improved model, the modulus decay (or damping ratio increasing) coefficient $k_{1}$ and the maximum damping ratio $\lambda_{\max }$ have been used to reflect the decaying relationship of modulus and the increasing relationship of damping ratio with the increase of soil shear strain. The improved model is described using the following formulas:

$$
\begin{aligned}
G & =\frac{G_{\max }}{1+k_{1} \gamma_{c}}, \\
G_{\max } & =k_{2} P_{a}\left(\frac{\sigma_{0}^{\prime}}{P_{a}}\right)^{n}, \\
\lambda & =\lambda_{\max } \frac{k_{1} \gamma_{c}}{1+k_{1} \gamma_{c}},
\end{aligned}
$$

where $P_{a}$ is the standard atmospheric pressure $(101.3 \mathrm{kPa})$; $\sigma_{0}^{\prime}$ is the mean effective stress of soil; $G_{\max }$ is the maximum shear modulus, $k_{2}$ and $n$ are the dynamic shear modulus coefficient and index; and $\gamma_{c}$ is the reference shear strain, and it is calculated by

$$
\gamma_{c}=\frac{\gamma}{\left(\sigma_{0}^{\prime} / P_{a}\right)^{1 / 2}}
$$

where $\gamma$ is the dynamic shear strain of soil.

There are two key variables in the equivalent nonlinear visco-elastic dynamic model, dynamic shear modulus $G$, and damping ratio $\lambda$ which are associated with the dynamic shear strain of soil and are used to reflect the nonlinear elasticity and viscosity of soil under dynamic load. Dynamic shear modulus and damping ratio are calculated by equations (20) and (22). All four parameters of the model $\left(k_{1}, k_{2}, n\right.$, and $\left.\lambda_{\max }\right)$ can be defined by a group of dynamic triaxial tests or resonant column tests [16].

In the improved equivalent nonlinear visco-elastic model, dynamic shear modulus coefficient $k_{2}$ and index $n$ are used to define the maximum dynamic shear modulus $G_{\max }$ as equation (20). Although they can be defined by approach of the laboratory tests as in the above description, the values of $k_{2}$ and $n$ defined by laboratory tests are difficult to reflect the actual dynamic deformation characteristics of soil in the ground comprehensively and reasonably, and they should be replaced by the results of field testing if the testing is performed carefully and generally. Firstly, the in-situ structural property of soil which has an important effect on the dynamic deformation characteristics of soil cannot be represented suitably in laboratory tests. Secondly, although some physical properties of soil (such as the natural compactness) can be represented suitably in laboratory tests through adjusting the experimental condition, the physical properties of soil are discrete in the whole range of the ground, and they can be described by limited experimental working conditions. So, the results of laboratory tests in which experimental working conditions are limited cannot reflect the real dynamic deformation characteristics of soil overall for the whole ground. The corresponding characteristic parameters defined by the method of field cross-hole wave velocity tests are representative entirely, because the shear wave velocity of soil layer is the entirety reflection of soil's dynamic deformation characteristics in field site.

Based on the above described reasons, the dynamic deformation characteristic parameters of soil (for maximum shear modulus) used in the following calculation analysis are defined based on the results of field cross-hole wave velocity tests as presented in Figure 3. In field exploration of the project, many field cross-hole wave velocity tests are performed, and the testing results are credible. The maximum shear modulus $G_{\max }$ of soil can be calculated by equation (24) when the shear wave velocity of soil layer $v_{s}$ is known,

$$
G_{\max }=\rho v_{s}^{2}
$$

where $\rho$ is the natural density of soil.

Because the decaying relationship of soil dynamic shear modulus (or the increasing relationship of soil damping ratio) with the increasing of soil dynamic shear strain is difficult to be determined by the method of field testing, the modulus decay (or damping ratio increasing) coefficient $k_{1}$ which reflects the relationship of dynamic shear modulus and damping ratio with dynamic shear strain and the maximum damping ratio $\lambda_{\max }$ still need to be defined by the laboratory tests. Based on the equivalent nonlinear visco-elastic dynamic model improved by ZhuJiang Shen, soil dynamic shear modulus and damping ratio of any soil layers in the ground model can be calculated using the mean effective stress state of soil in any layers which can be defined by the static finite element method, the shear wave velocity of soil layers which can be defined by the field cross-hole wave velocity tests, and the relationship parameters of dynamic shear modulus and damping ratio with the dynamic shear strain of any type soils which can be defined by the laboratory tests. The modulus decay (or damping ratio increasing) coefficient $k_{1}$ and the maximum damping ratio $\lambda_{\max }$ of all soils in the ground model which is defined by the laboratory tests are shown as Table 1. 
TABLe 1: Maximum damping ratio $\lambda_{\max }$ and modulus decay (or damping ratio increasing) coefficient $k_{1}$ of soils in ground.

\begin{tabular}{lcc}
\hline Soils & $\lambda_{\max }$ & $k_{1}$ \\
\hline Layer (4), modern alluvial deposit sand gravel stratum layer & 0.238 & 17.6 \\
Layer (3)-3, fluvio-lacustrine deposits sand layer containing gravel & 0.278 & 5.5 \\
Layer (3)-2, fluvio-lacustrine deposits silty clay layer & 0.293 & 6.3 \\
Layer (3)-1, fluvio-lacustrine deposits sand layer containing gravel & 0.271 & 5.7 \\
Layer (2), alluvial-pluvial and stacking sand layer containing crush (or pebble) & 0.245 & 15.2 \\
Layer (1), moraine and glacial relics stacking crushed-rock layer & 0.240 \\
\hline
\end{tabular}

3.3. Inputting Seismic Motion. The input seismic wave from bedrock is the site wave determined by the regional seismic hazard analysis. The site wave considers the impact of the regional seismic environment such as the geological structure of the engineering site, including the characteristics of the main potential sources and the attenuation characteristics in propagation. The uniform probability method is used to determine the seismic acceleration response spectrum of different probability levels in the engineering field, and the acceleration time history is generated accordingly. The horizontal vibration peak acceleration of the free surface of the wave bedrock of the site is $0.54 \mathrm{~g}$, and the absolute acceleration response spectrum is shown in Figure 4(a). Considering the regional ground motion characteristics comprehensively, the time history of ground motion acceleration generated from the acceleration response spectrum is $82 \mathrm{~s}$, as shown in Figure $4(\mathrm{~b})$. It can be seen from Figure 4 that the acceleration response spectrum has a wide spectrum platform, the first characteristic period is about $0.1 \mathrm{~s}$, and the second characteristic period (the falling inflection point of the response spectrum platform) is about $0.6 \mathrm{~s}$. Although the ground motion lasts up to $81 \mathrm{~s}$, the main body vibration occurs. In the first $40 \mathrm{~s}$ of the earthquake, the vibration amplitude was smaller in the later period.

3.4. Basic Calculation Results of the Ground Seismic Analysis and the Primary Analysis. Acceleration peak values of soil layers in different depths of the ground are shown in Figure 5(a), and the distribution of corresponding acceleration amplification factors along the vertical direction in the ground is shown in Figure 5(b). The acceleration amplification factors of soil layers are based on the acceleration peak value of site earthquake which is the vibration progress of rock outcrop in an earthquake $(0.54 \mathrm{~g})$. Comparison of the horizontal vibration acceleration time history and the corresponding acceleration spectra of soil layers at different heights in the ground is shown in Figure 6.

From Figure 5, super-deep overburden layer has a significant reducing effect on the seismic motion inputting from deep bedrock, the peak value of acceleration on the bedrock surface underground is far below to it on the bedrock outcrop (site earthquake) because of the restrictive effects of super-deep overburden layer on vibration of bedrock surface, and the vibration amplitude of soil layers in any height of the ground is lower than the bedrock surface. The vibration acceleration amplification factor of soil layers decreases first and then increases with the growth of soil layers' altitude. The acceleration amplification factor on the ground surface is only about 0.6 , and the acceleration peak value is far below the inputting value. The main reason is that the overburden layer is softer than the bedrock and the overburden layer is super deep; the super-deep soft soil layers dissipate the energy of inputting seismic motion from bedrock largely, so the vibration amplitude of soil layers is lower than it on the bedrock surface under overburden layer ground. Because the gravel-bearing sand (with silty sand) layer (layer (3)-1 and layer (3)-3) of the river-lacustrine facies sedimentation is interspersed with the relatively hard silty clay layer (layer (3)-2) of the river-lacustrine sedimentation, as a result, the curve has a certain degree of bending abrupt change at the soil elevation.

From Figure 6, long-period components of the acceleration response spectra increase as the growth of soil layers' altitude. Shape of the response spectra curve changes from single peak type to multipeak or plateau type, and the characteristic period corresponding to the maximum value of response spectra changes bigger gradually. The second characteristic period (decreasing inflection point of response spectra platform) of response spectra is about $2.0 \mathrm{~s}$ on the ground surface that is larger than the value on the bedrock surface (about $0.6 \mathrm{~s}$ ). Based on the response spectra shape on the ground surface, it can be known that vibration of the soil layer on ground surface presents a slowly sloshing station relatively to it on the bedrock surface.

Although acceleration amplitude of the seismic motion inputting from bedrock is reduced greatly because of the super-deep overburden layer, long-period components of its' acceleration response spectra change prominently, and the characteristic period of seismic motion changes larger. Long-period components of the acceleration response spectra change prominently on the ground surface, which is disadvantageous to towering structures on ground surface in which natural vibration period is relatively large, such as in the 1985 Mexican Earthquake [17]. Although Mexico City was $400 \mathrm{~km}$ from epicenter of the Mexican Earthquake, that is, a large distance, also lots of towering structures in the city were destroyed seriously for the earthquake, and most destroyed tower structures were constructed on the lacustrine deposits deep overburden soil layer. Although the deep soil layer reduced acceleration amplitude of the earthquake greatly (the peak value of acceleration on ground surface is only $0.15 \mathrm{~g}$ ), but the characteristic period of earthquake increased greatly for the deep soil layer, and the characteristic period of seismic motion on the ground surface changed close to the natural vibration period of towering structures. That is the main reason for serious damage in the earthquake. 


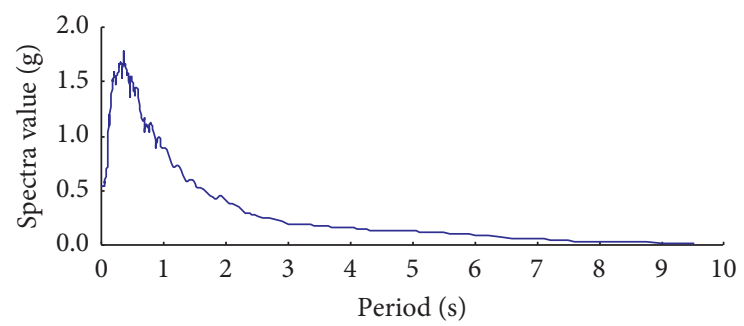

(a)

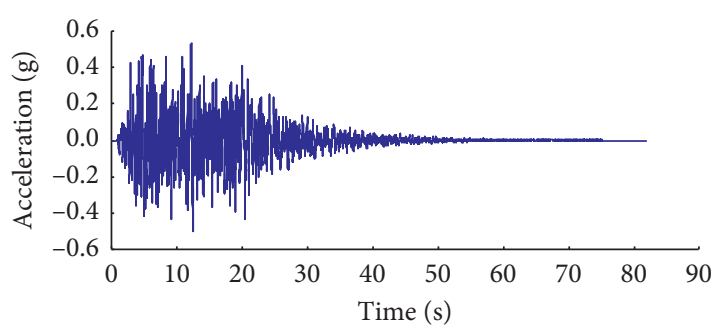

(b)

FIgURE 4: Inputting seismic motion of the ground seismic analysis. (a) Acceleration spectra (damping ratio is 0.05). (b) Acceleration time history.

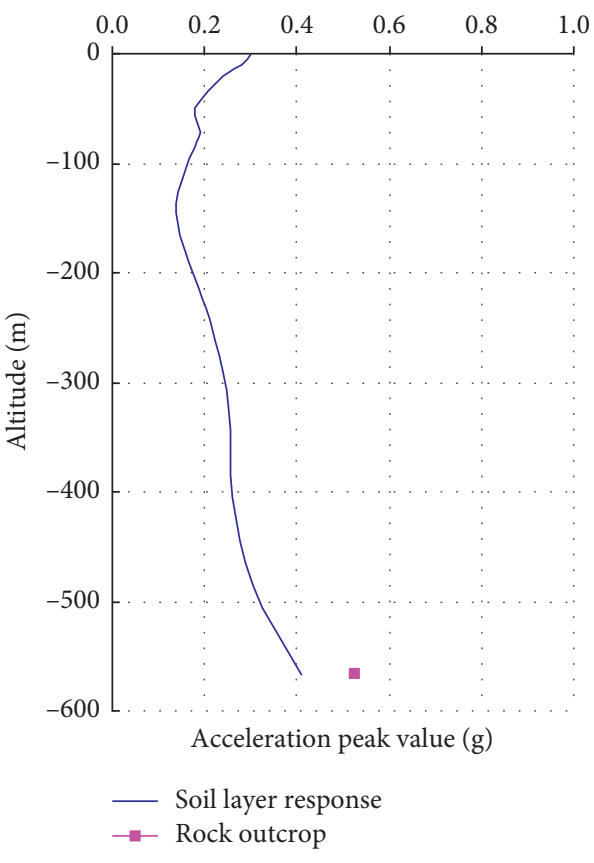

(a)

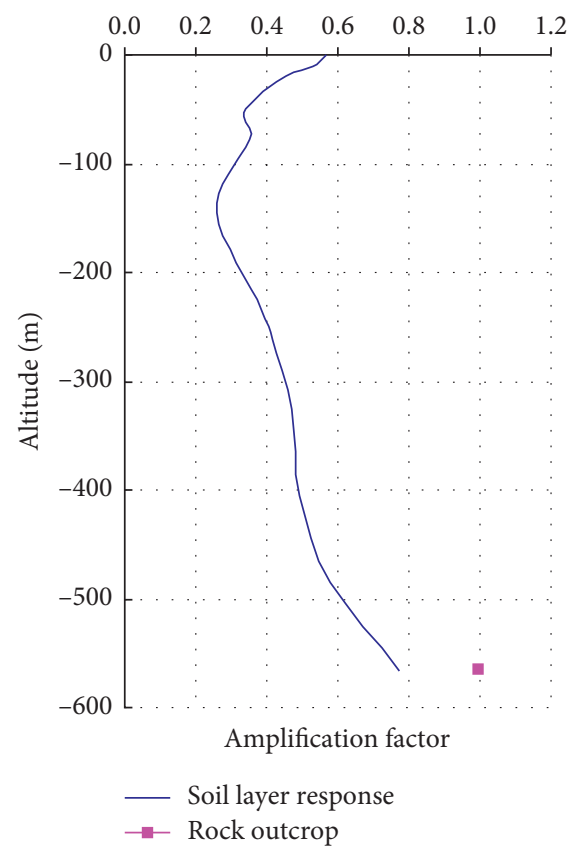

(b)

FIGURE 5: Distribution of the acceleration peak values and the corresponding amplification factors of soil layers in the ground along the vertical direction (the altitude of ground surface is $0 \mathrm{~m}$ and the altitude of bedrock surface is $-566.9 \mathrm{~m}$ ). (a) Acceleration peak value. (b) Acceleration amplification factor.
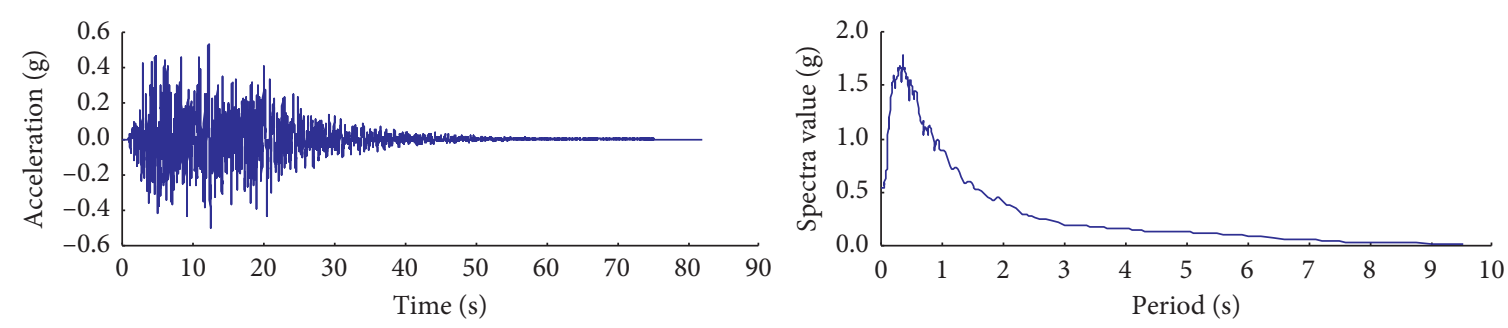

(a)
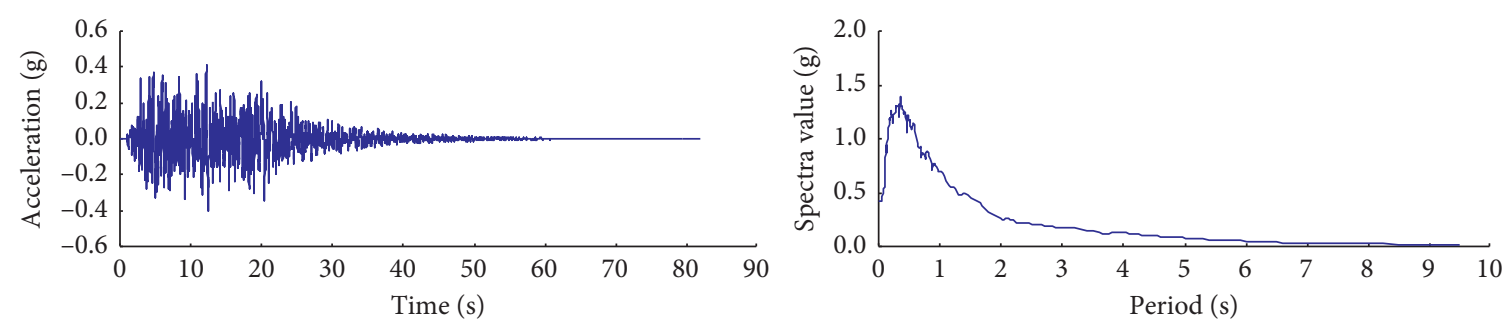

(b)

Figure 6: Continued. 

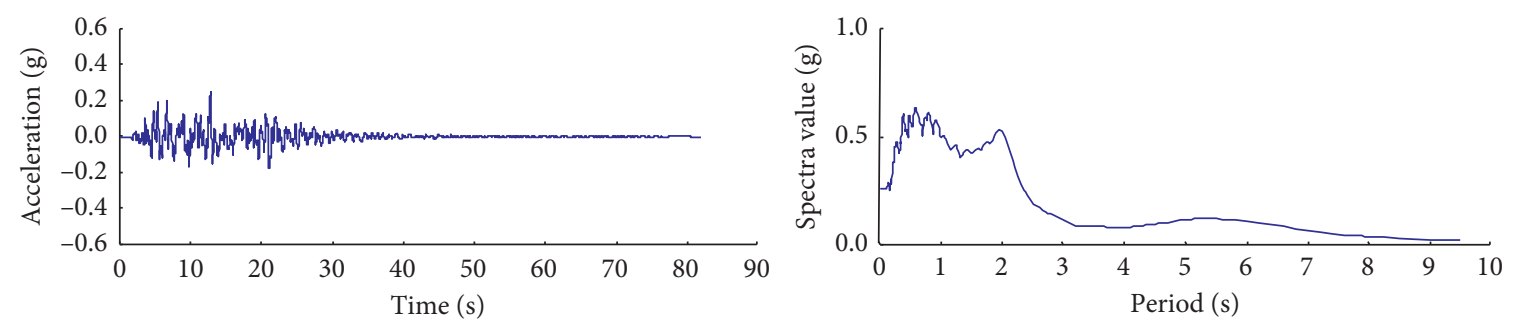

(c)
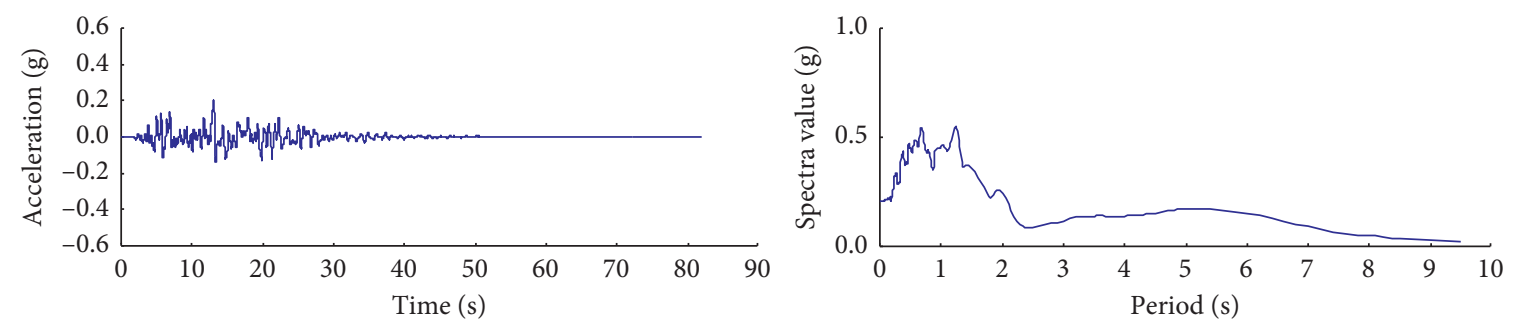

(d)
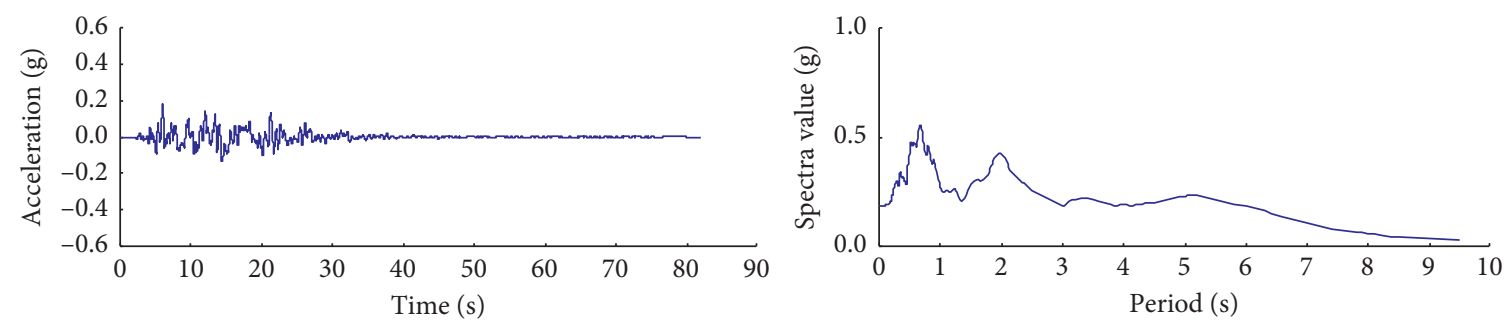

(e)
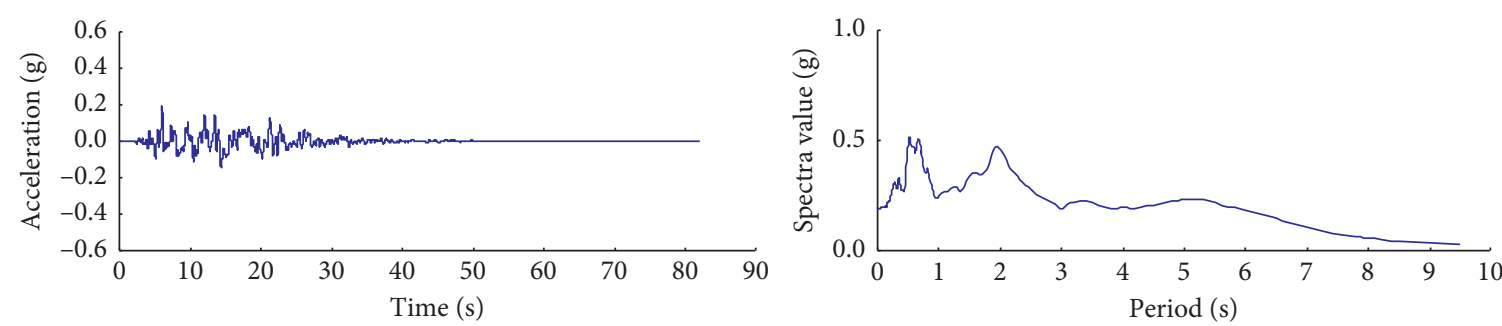

(f)
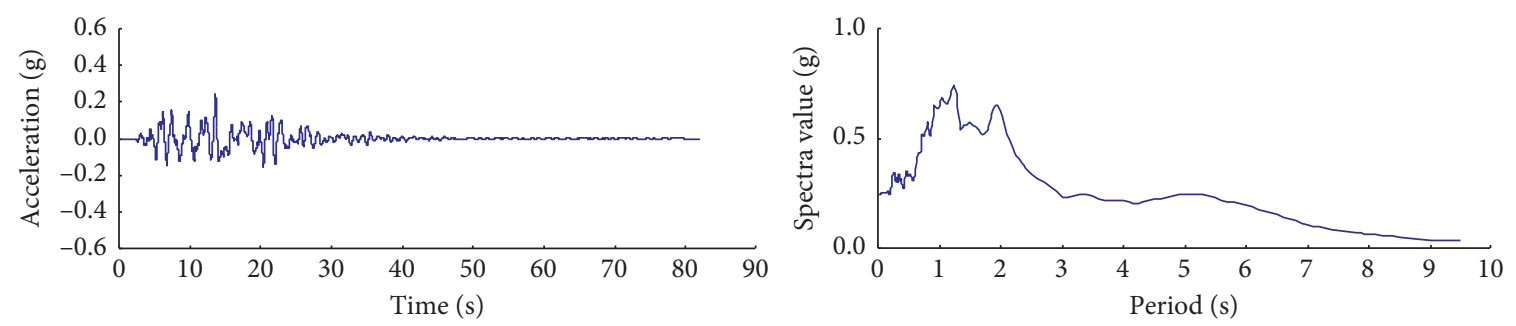

(g)

Figure 6: Continued. 

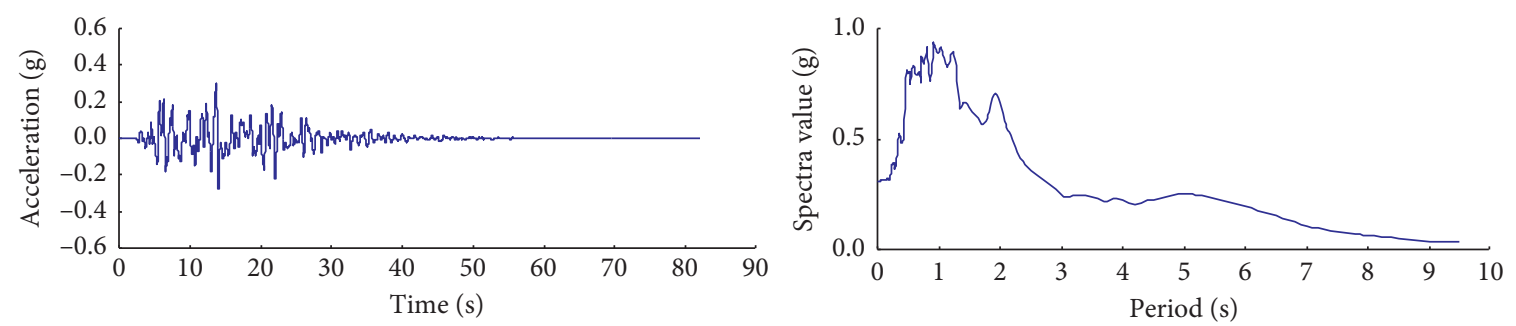

(h)

FIGURE 6: Comparison of the vibration acceleration time history and the corresponding acceleration spectra (damping ratio is 0.05 ) of soil layers at different altitude in the ground. (a) Inputting seismic motion (surface of the rock outcrop). (b) Surface of the bedrock under overburden layer ground (the height to bedrock surface is $0 \mathrm{~m}$ ). (c) Surface of layer (1) (the height to bedrock surface is $241 \mathrm{~m}$ ). (d) Surface of layer (2) (the height to bedrock surface is $334 \mathrm{~m}$ ). (e) Surface of layer (3)-1 (the height to bedrock surface is $481 \mathrm{~m}$ ). (f) Surface of layer (3)-2 (the height to bedrock surface is $495 \mathrm{~m}$ ). (g) Surface of layer (3)-3 (the height to bedrock surface is $546 \mathrm{~m}$ ). (h) Surface of layer (4) (the height to bedrock surface is $566.9 \mathrm{~m}$ ).

3.5. Impacts of Inputting Seismic Motion from Bedrock on the Ground Seismic Motion Characteristics. The seismic motion transmitting characteristics of overburden layer under earthquake from bedrock under ground is influenced dually by the structural characteristics of overburden layer ground and the seismic motion characteristics of inputting earthquake [18-23]. The influencing rule of seismic motion characteristics of inputting earthquake on seismic motion transmitting characteristics of overburden layer is studied through investigating the difference of ground seismic motion characteristics under different earthquakes. Seismic motion characteristics of the earthquake can be represented by the intensity of earthquake (seismic motion amplitude), the spectral characteristics of earthquake, and the vibration duration of earthquake.

A series seismic response analysis of the ground is conducted in condition that the acceleration peak value of earthquake is adjusted in the range of $0.1 \mathrm{~g} \sim 0.9 \mathrm{~g}$ and the shape of earthquake acceleration time history becomes unchangeable (the spectral characteristics and the vibration duration of earthquake become unchangeable). Acceleration peak values and corresponding acceleration amplification factors of the soil layers in different depths of ground under earthquakes in which acceleration peak values are different, as shown in Figure 7. Acceleration response amplitude of the ground increases with the increase of the amplitude of inputting earthquake, and the difference of soil layer acceleration response amplitude under different intensity earthquakes decreases first and then increases with the growth of soil layers' altitude. Acceleration amplification factors of the soil layers decrease with the increase of the amplitude of inputting earthquake, which is caused by the nonlinear dynamic characteristics of ground soils mainly. When the amplitude of inputting earthquake is relatively low (lower than $0.2 \mathrm{~g}$ ), the vibration amplitude of ground surface is magnified slightly contrasting with bedrock inputting (site earthquake), and the vibration amplitude of ground surface is reduced contrasting with the site earthquake when the amplitude of inputting earthquake is higher than $0.2 \mathrm{~g}$. On the other hand, from the results of the response spectrum analysis, the influence of deep overburden layer ground on the acceleration response spectra shape changes more obviously when the inputting earthquake changes strongly, and the amplification effects of soil layer on the long-period seismic motion components are outstanding in strong earthquake.

In order to investigate the influence of inputting earthquake wave shape (containing the dual influencing of earthquake spectral characteristics and vibration duration) on seismic motion transmitting characteristics of soil layer ground, the ground seismic response analysis when the ground is under the other earthquake is performed contrasting with the site earthquake of the example project. The comparative earthquake is a site earthquake of the other project and vibration duration of the earthquake is $26.0 \mathrm{~s}$, and the acceleration peak value is adjusted to $0.53 \mathrm{~g}$. Acceleration spectra of the earthquake and the acceleration time history, which is generated according to the acceleration spectra, are shown in Figure 8. Contrasting with Figure 5, characteristic period of acceleration spectra peak value of the comparative earthquake is below than the site earthquake of the example project. The first characteristic period is $0.1 \mathrm{~s}$, but the second characteristic period (decreasing inflection point of response spectra platform) is about $0.3 \mathrm{~s}$ that is far lower than the site earthquake of the example project. So, short period components of the comparative earthquake are more obvious compared with the site earthquake of the example project. On the other hand, vibration duration of the comparative earthquake is shorter more than the site earthquake of the example project. The spectral characteristics and the vibration duration of two earthquakes have a significant difference.

Comparison of the acceleration amplification factor of soil layers in different heights of the ground under two different earthquakes is shown in Figure 9. From the figure, the vibration amplitude on the bedrock surface under two earthquakes is basically quite, but the vibration amplitude of soil layers induced by different earthquake waves transmitting in overburden layer ground is different obviously, and the vibration amplitude of soil layers under comparative earthquake is far below than the site earthquake of the example project. Reasons of that can be summarized as 


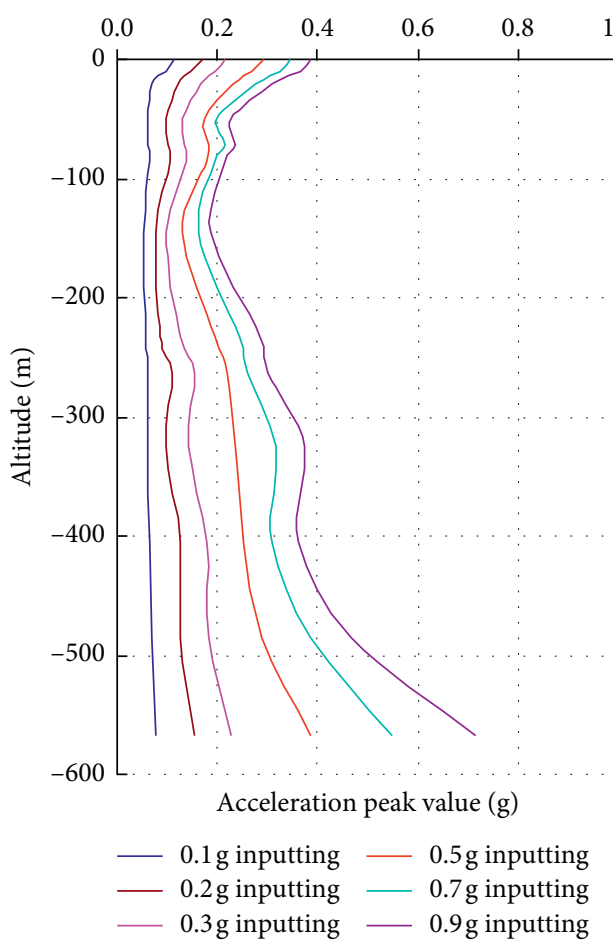

(a)

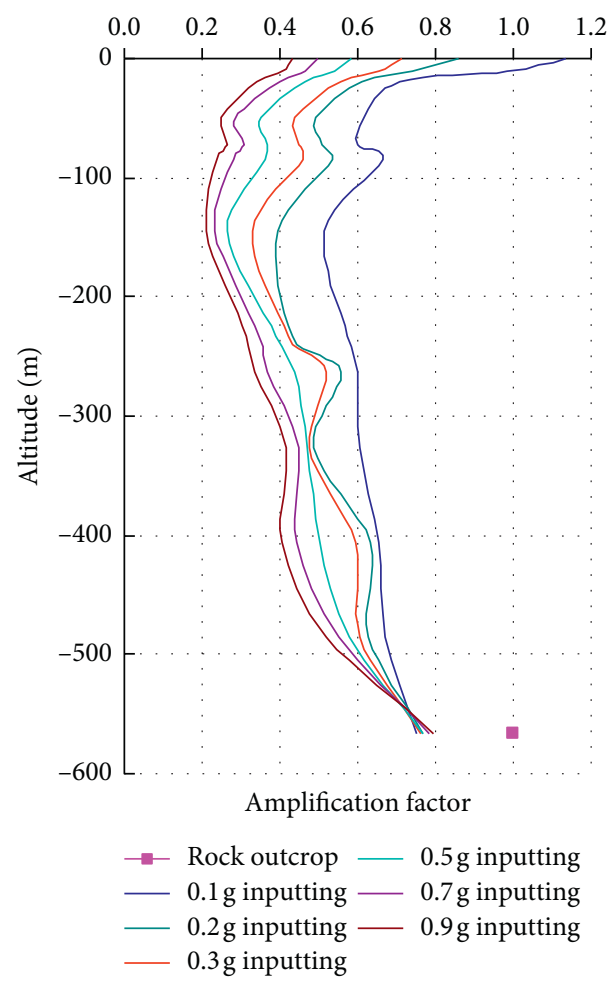

(b)

Figure 7: Impacts of seismic motion intensity on the site amplification effects of overburden layer. (a) Acceleration peak value. (b) Acceleration amplification factor.

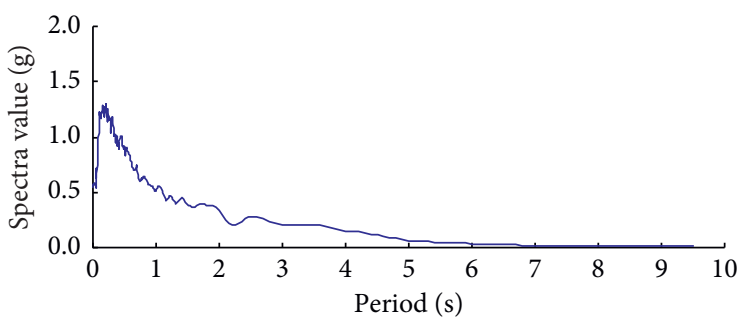

(a)

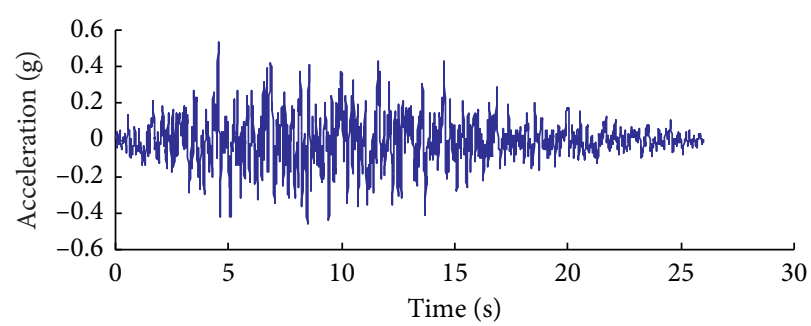

(b)

Figure 8: Inputting seismic motion of the contrasting analysis. (a) Acceleration spectra (damping ratio is 0.05). (b) Acceleration time history.

follows: (1) the second characteristic period (decreasing inflection point of response spectra platform) of the site earthquake of the example project is higher than the comparative earthquake and the long-period components of the earthquake are outstanding; all these seismic motion characteristics of the site earthquake of example project are adaptive with the structural characteristics of super-deep overburden layer ground system in which first natural vibration period is relatively high. When the characteristic period of the earthquake is close to the structural first natural vibration period of overburden layer ground, vibration of the ground is stronger. (2) Vibration of soil layers is the dual results of incident wave and reflected wave; vibration amplitude of soil layers is the superposition of incident wave amplitude and reflected wave amplitude. Because vibration duration of the site earthquake of the example project is longer than the comparative earthquake, the superposition effects of soil layers vibration are more obvious when the earthquake transmits in the super-deep ground. So, the vibration amplitude of the soil layers under the site earthquake of the example project is stronger than the comparative earthquake.

3.6. Impacts of Seismic Motion Inputting Interface on Results of the Ground Seismic Response Analysis. Based on the results of ground seismic analysis for two deep soil layer grounds in which thickness is $100 \mathrm{~m}$ and $280 \mathrm{~m}$, Guo-Xing Chen suggests that the interface of soil layers whose shear velocity is $500 \mathrm{~m} / \mathrm{s}$ could be regarded as the interface of seismic motion inputting in ground seismic analysis [24]. For the typical drilling of example ground that the calculation model of 


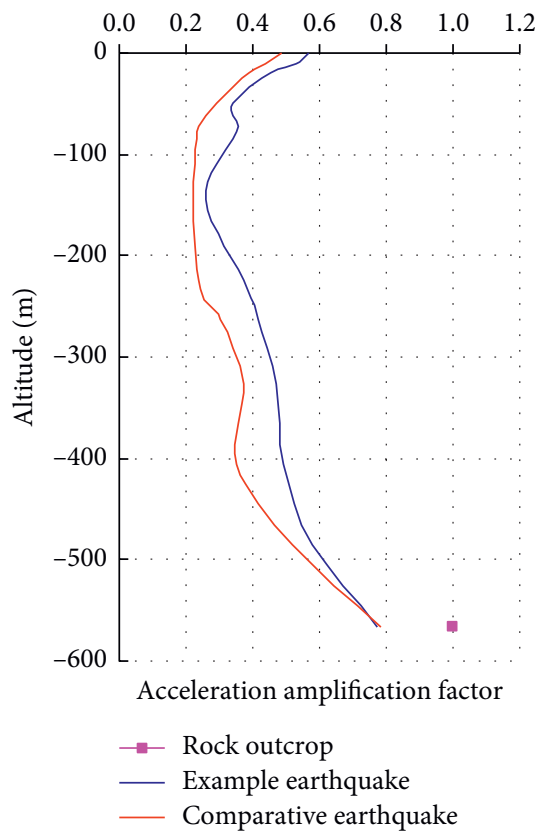

FIGURE 9: Impacts of the inputting earthquake shape on the seismic motion transmitting characteristics (containing the dual influencing of earthquake spectral characteristics and vibration duration).

ground seismic response analysis is established based on it, the interface of soil layers in which shear velocity is $500 \mathrm{~m} / \mathrm{s}$ is located in the interior of layer (3)-1, and depth of the interface is $128 \mathrm{~m}$ under the ground surface. In the following, some ground models for ground seismic response analysis for example ground are established in which seismic motion inputting interfaces are on the surface of layer (3)-1 (underground depth $85.1 \mathrm{~m}$ ), the $500 \mathrm{~m} / \mathrm{s}$ shear wave velocity interface (inside layer (3)-1, underground depth $128 \mathrm{~m}$ ), the surface of layer (2) (underground depth $232.8 \mathrm{~m}$ ), and the surface of bedrock (underground depth $566.92 \mathrm{~m}$ ). The ground seismic response analysis for these ground models under the same earthquake as before is performed to study the influencing rule of the location of seismic motion inputting interface on the results of ground seismic response analysis. Comparison of the acceleration magnified factors of soil layers along the vertical direction in the ground is shown in Figure 10 when the different interfaces have been as the seismic motion inputting interface for the ground seismic response analysis.

From Figure 10 and combining with the acceleration spectra analysis, it can be known that the acceleration response amplitude of soil layers in the ground increases greatly when the altitude of seismic motion inputting interface changes higher, and the shape of acceleration spectra is not affected obviously by the location of seismic motion inputting interface. The calculation results show that simply selecting the $500 \mathrm{~m} / \mathrm{s}$ shear wave velocity interface as the ground motion input interface will significantly overestimate the amplification effect of the site on the input ground motion of the bedrock. Although the soil is hard relatively when the shear velocity of soil layer is over $500 \mathrm{~m} / \mathrm{s}$ or even

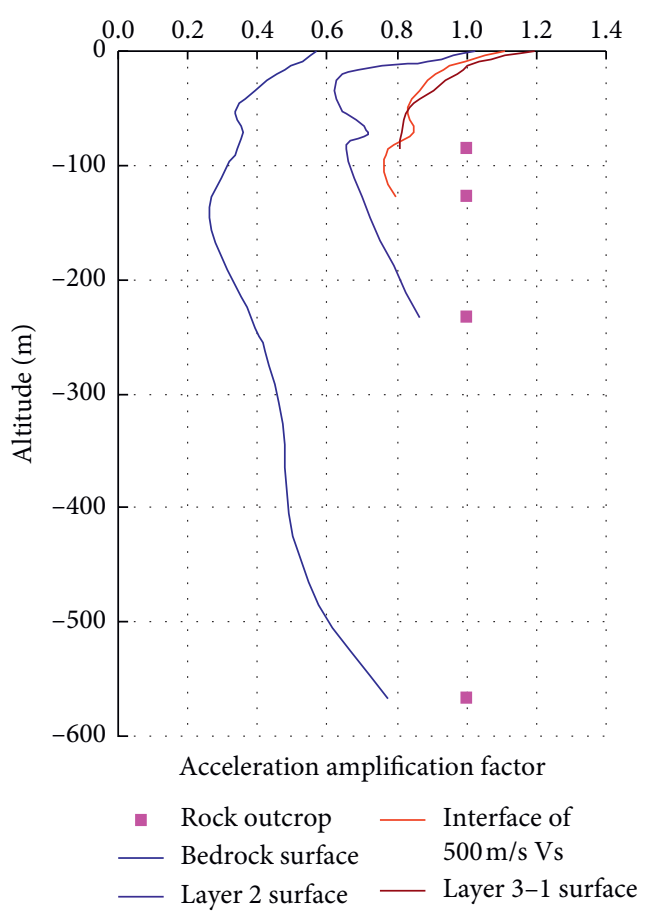

FIGURE 10: Impacts of seismic motion inputting interface on results of the ground seismic response analysis.

more higher, the visco-elastic characteristics and the dynamic deformation nonlinear characteristics of soil are still significant, so the energy dissipation effects of these hard soil layers in which shear velocity is over $500 \mathrm{~m} / \mathrm{s}$ on the earthquake from the bedrock is still nonnegligible. For those super-deep overburden soil layer grounds, it is vital selecting the real hard bedrock surface under soil layer ground as the inputting interface of seismic motion in the ground seismic response analysis.

\section{Ground Seismic Response Analysis considering the Coupling Influence of Soil Layer Thickness and Soil Shear Velocity}

4.1. Research Thinking and Calculation Model. As the description of the abovementioned ground seismic response analysis theory, seismic motion transmitting characteristics of overburden layer under earthquake from bedrock under the ground is influenced dually by the structural characteristics of overburden layer ground system and the seismic motion characteristics of inputting earthquake. The above results of the ground seismic motion characteristics example analysis for the real super-deep overburden layer have shown that seismic motion characteristics of deep overburden layer ground are influenced greatly by the seismic motion characteristics of inputting earthquake (such as the seismic motion amplitude, the spectral characteristics, and the vibration duration of earthquake). For another influencing factor of seismic ground motion transmitting characteristics, the structural characteristics of overburden layer ground system are controlled mainly by two 
influencing factors, the thickness of overburden layer ground and the dynamic deformation characteristics of soil. Structural geometric characteristics of the ground are influenced by the thickness of soil layer, structural material characteristics of the ground is influenced by the dynamic deformation characteristics of soil, and the structural characteristics of overburden layer ground are determined by the geometric and material characteristics of ground dually $[25,26]$.

As shown in the above description, the dynamic deformation characteristics of soil are represented by the maximum shear modulus of soil and its' decay characteristics with the increasing of soil shear strain, and the maximum shear modulus of soil can be represented indirectly by the values of shear wave velocity which is obtained from the field cross-hole wave velocity testing. Normally, the shear wave velocity of soil layer is not uniform along the vertical direction, and the vertical structural characteristics of the ground are widely existed. The shear wave velocity characteristics of the ground as a whole (or the hardness of whole ground) can be represented grossly by the mean shear wave velocity of the ground which is controlled dually by the shear wave velocity of all soil layers and the corresponding thickness of soil layers as shown in equation (25). The hardness of the overburden layer ground can be shown qualitatively by the mean shear wave velocity of the ground basically, and the mean shear wave velocity of the ground is used to represent the ground characteristics qualitatively in some Chinese structure antiseismic design codes [27, 28]. Although the seismic motion transmitting characteristics of overburden layer ground is influenced by the distribution characteristics of soil layer shear wave velocity along the vertical direction in the ground to a certain degree, the mean shear wave velocity of the ground is still used to judge the seismic motion characteristics qualitatively in those codes. On the other hand, because the influencing analysis of the shear wave velocity on the ground seismic motion characteristics cannot be realized easily based on the ground model which has structural features along the vertical direction in the real study work, it is necessary using the mean shear wave velocity to represent the hardness of ground in the influencing analysis of soil layer shear wave velocity (the maximum dynamic shear modulus of soil) on the ground seismic motion characteristics. The mean shear wave velocity of the ground is used to represent the shear wave velocity characteristics of the ground as a whole (or the hardness of the whole ground) in the coupling influencing analysis of the ground soil layer thickness and shear wave velocity on the ground seismic motion characteristics:

$$
v_{s e}=\frac{d_{0}}{\sum_{i=1}^{n}\left(d_{i} / v_{s i}\right)},
$$

where $v_{s e}$ is the mean shear wave velocity of ground, $d_{0}$ is the thickness of soil ground, $d_{i}$ is the thickness of soil layer $i, v_{s i}$ is the shear wave velocity of soil layeri, and $n$ is the number of soil layers in the ground model.

When the thickness of the ground is a certain value, the influence of ground shear wave velocity (or the hardness of whole ground) on the seismic motion characteristics of the ground is investigated through the method of adjusting the mean shear wave velocity of ground. When the mean shear wave velocity of ground is a certain value, the influence of soil layer ground thickness on the seismic motion characteristics of the ground is investigated through the method of adjusting the soil layer thickness of ground. In order to investigate whether the coupling influencing of the soil layer ground thickness and shear wave velocity on the ground seismic motion characteristics have existed and find the coupling influencing rule further more, lots of calculation work conditions are designed to do the ground seismic response analysis in which thickness and shear wave velocity of the ground model are changed simultaneously.

Range of soil layer ground thickness is $5 \sim 600 \mathrm{~m}$, and the thickness interval of ground models is $20 \mathrm{~m}$. Some uniform ground models whose shear wave velocity characteristics are represented by the mean shear wave velocity are established. When the mean shear wave velocity is above $500 \mathrm{~m} / \mathrm{s}$, thickness of the sublayer in the ground models is $8 \mathrm{~m}$. When the mean shear wave velocity is below $500 \mathrm{~m} / \mathrm{s}$, thickness of the sublayer in the ground models is $5 \mathrm{~m}$, and the minimum number of ground sublayers is 10 . The value of mean shear wave velocity of the uniform ground is changed uniformly from $530 \mathrm{~m} / \mathrm{s}$ which is the value of mean shear wave velocity of the above example super-deep overburden layer ground, and the range of soil layer ground mean shear wave velocity is $212 \sim 1223 \mathrm{~m} / \mathrm{s}$ which covers the mean shear wave velocity range of normal overburden layer grounds basically. The critical state of the uniform soil layer ground is the uniform bedrock ground when the shear wave velocity is large enough, and the shear wave velocity interval of ground models is $53 \mathrm{~m} /$ s. The calculation work conditions of coupling influencing analysis of soil layer ground thickness and shear wave velocity are shown as Table 2, and it gives the values of thickness and shear wave velocity of the ground models.

The soil damping characteristics and the decay characteristics of soil dynamic shear modulus with dynamic strain increasing are the important representation of soil dynamic deformation characteristics, and they are related with the shear wave velocity of soil (or maximum dynamic shear modulus). But the dynamic modulus decay (or damping ratio increasing) coefficient $k_{1}$ and maximum damping ratio $\lambda_{\max }$ representing the dynamic modulus decay characteristics and the damping characteristics of soil are assumed to be unchangeable with the increasing of dynamic shear strain in order to be easy for calculation and contrastive analysis. The value of soil modulus decay (or damping ratio increasing) coefficient $k_{1}$ is 10.0 fixedly, the soil maximum damping ratio $\lambda_{\max }$ is 0.255 fixedly, and the natural soil density is $2.0 \mathrm{~g} /$ $\mathrm{cm}^{3}$ fixedly.

In order to be easy for calculation and contrastive analysis similarly, the inputting seismic motion of ground seismic response analysis is still the site earthquake of the example project.

4.2. Basic Calculation Results Representation. Seismic motion characteristics of the grounds in which thickness and 
TABLE 2: Influence of soil ground thickness and shear wave velocity on acceleration magnified factors on ground free surface.

\begin{tabular}{|c|c|c|c|c|c|c|c|c|c|c|c|c|c|c|c|c|c|c|c|c|}
\hline \multirow{3}{*}{$\begin{array}{c}\text { Soil } \\
\text { ground } \\
\text { thickness } \\
(\mathrm{m})\end{array}$} & \multicolumn{20}{|c|}{ Surface } \\
\hline & \multicolumn{20}{|c|}{ Mean shear wave velocity of ground $(\mathrm{m} / \mathrm{s})$} \\
\hline & 212 & 265 & 318 & 371 & 424 & 477 & 530 & 583 & 636 & 699 & 742 & 795 & 848 & 901 & 954 & 1007 & 1060 & 1113 & 1166 & 1223 \\
\hline 5 & 1.707 & 1.425 & 1.161 & 1.109 & 1.049 & 1.008 & 1.008 & 1.024 & 1.030 & 1.028 & 1.024 & 1.021 & 1.018 & 1.016 & 1.014 & 1.012 & 1.011 & 1.010 & 1.009 & 1.009 \\
\hline 10 & 1.846 & 1.994 & 1.833 & 1.646 & 1.521 & 1.328 & 1.190 & 1.106 & 1.037 & 1.015 & 1.006 & 0.988 & 0.981 & 0.989 & 0.994 & 0.999 & 1.002 & 1.004 & 1.005 & 1.005 \\
\hline 20 & 1.323 & 1.637 & 1.783 & 1.762 & 1.637 & 1.780 & 1.723 & 1.611 & 1.419 & 1.288 & 1.252 & 1.214 & 1.151 & 1.076 & 1.052 & 1.033 & 1.013 & 0.996 & 0.991 & 0.989 \\
\hline 40 & 0.985 & 1.189 & 1.196 & 1.288 & 1.462 & 1.621 & 1.688 & 1.591 & 1.512 & 1.425 & 1.333 & 1.350 & 1.377 & 1.276 & 1.191 & 1.169 & 1.110 & 1.092 & 1.080 & 1.060 \\
\hline 60 & 0.721 & 0.890 & 1.019 & 1.191 & 1.254 & 1.201 & 1.251 & 1.356 & 1.495 & 1.548 & 1.524 & 1.456 & 1.379 & 1.304 & 1.234 & 1.202 & 1.135 & 1.111 & 1.120 & 1.096 \\
\hline 80 & 0.546 & 0.733 & 0.896 & 1.030 & 1.044 & 1.214 & 1.235 & 1.229 & 1.250 & 1.269 & 1.275 & 1.357 & 1.384 & 1.410 & 1.359 & 1.317 & 1.247 & 1.194 & 1.151 & 1.111 \\
\hline 100 & 0.443 & 0.572 & 0.752 & 0.911 & 0.994 & 1.026 & 1.066 & 1.219 & 1.235 & 1.221 & 1.236 & 1.198 & 1.182 & 1.194 & 1.237 & 1.276 & 1.272 & 1.262 & 1.210 & 1.177 \\
\hline 120 & 0.376 & 0.485 & 0.578 & 0.768 & 0.915 & 0.953 & 1.033 & 1.067 & 1.092 & 1.170 & 1.168 & 1.189 & 1.172 & 1.189 & 1.193 & 1.203 & 1.210 & 1.138 & 1.167 & 1.142 \\
\hline 140 & 0.334 & 0.457 & 0.588 & 0.597 & 0.781 & 0.912 & 0.920 & 1.016 & 1.004 & 1.010 & 1.076 & 1.083 & 1.088 & 1.095 & 1.097 & 1.102 & 1.108 & 1.112 & 1.108 & 1.076 \\
\hline 160 & 0.313 & 0.390 & 0.505 & 0.634 & 0.630 & 0.791 & 0.909 & 0.921 & 0.994 & 1.004 & 1.034 & 1.013 & 1.052 & 1.055 & 1.063 & 1.067 & 1.079 & 1.079 & 1.081 & 1.071 \\
\hline 180 & 0.310 & 0.362 & 0.465 & 0.538 & 0.644 & 0.655 & 0.799 & 0.902 & 0.915 & 0.964 & 0.983 & 0.986 & 1.002 & 1.019 & 1.030 & 1.053 & 1.071 & 1.077 & 1.078 & 1.070 \\
\hline 200 & 0.294 & 0.340 & 0.411 & 0.523 & 0.611 & 0.643 & 0.676 & 0.805 & 0.899 & 0.913 & 0.938 & 0.980 & 0.964 & 0.939 & 0.957 & 1.023 & 1.069 & 1.073 & 1.074 & 1.055 \\
\hline 220 & 0.259 & 0.338 & 0.387 & 0.475 & 0.546 & 0.651 & 0.629 & 0.692 & 0.809 & 0.894 & 0.905 & 0.916 & 0.959 & 0.953 & 0.927 & 0.921 & 0.985 & 1.010 & 1.040 & 1.033 \\
\hline 240 & 0.223 & 0.335 & 0.370 & 0.430 & 0.534 & 0.576 & 0.668 & 0.627 & 0.705 & 0.816 & 0.884 & 0.891 & 0.894 & 0.932 & 0.942 & 0.918 & 0.931 & 0.937 & 0.947 & 0.981 \\
\hline 260 & 0.196 & 0.321 & 0.360 & 0.410 & 0.486 & 0.569 & 0.628 & 0.671 & 0.645 & 0.722 & 0.812 & 0.874 & 0.877 & 0.875 & 0.907 & 0.908 & 0.904 & 0.907 & 0.912 & 0.917 \\
\hline 280 & 0.179 & 0.294 & 0.361 & 0.400 & 0.447 & 0.541 & 0.573 & 0.663 & 0.660 & 0.659 & 0.728 & 0.811 & 0.863 & 0.864 & 0.857 & 0.877 & 0.882 & 0.894 & 0.895 & 0.899 \\
\hline 300 & 0.171 & 0.260 & 0.359 & 0.383 & 0.426 & 0.497 & 0.581 & 0.598 & 0.678 & 0.640 & 0.664 & 0.735 & 0.808 & 0.850 & 0.848 & 0.847 & 0.865 & 0.872 & 0.879 & 0.882 \\
\hline 320 & 0.168 & 0.235 & 0.346 & 0.381 & 0.423 & 0.462 & 0.551 & 0.588 & 0.642 & 0.676 & 0.629 & 0.669 & 0.737 & 0.802 & 0.836 & 0.833 & 0.837 & 0.850 & 0.855 & 0.861 \\
\hline 340 & 0.163 & 0.215 & 0.324 & 0.381 & 0.406 & 0.443 & 0.509 & 0.589 & 0.591 & 0.666 & 0.669 & 0.640 & 0.673 & 0.735 & 0.795 & 0.822 & 0.816 & 0.827 & 0.835 & 0.842 \\
\hline 360 & 0.153 & 0.201 & 0.296 & 0.377 & 0.398 & 0.440 & 0.476 & 0.556 & 0.602 & 0.619 & 0.675 & 0.654 & 0.649 & 0.676 & 0.732 & 0.786 & 0.808 & 0.808 & 0.817 & 0.822 \\
\hline 380 & 0.137 & 0.190 & 0.271 & 0.367 & 0.397 & 0.429 & 0.456 & 0.519 & 0.595 & 0.596 & 0.644 & 0.675 & 0.633 & 0.654 & 0.678 & 0.733 & 0.777 & 0.794 & 0.800 & 0.808 \\
\hline 400 & 0.121 & 0.188 & 0.251 & 0.350 & 0.399 & 0.416 & 0.453 & 0.489 & 0.564 & 0.613 & 0.602 & 0.658 & 0.665 & 0.648 & 0.659 & 0.678 & 0.732 & 0.767 & 0.781 & 0.794 \\
\hline 420 & 0.114 & 0.187 & 0.234 & 0.326 & 0.394 & 0.412 & 0.449 & 0.469 & 0.528 & 0.601 & 0.605 & 0.619 & 0.665 & 0.646 & 0.652 & 0.658 & 0.681 & 0.728 & 0.755 & 0.772 \\
\hline 440 & 0.108 & 0.183 & 0.221 & 0.300 & 0.386 & 0.412 & 0.435 & 0.462 & 0.501 & 0.571 & 0.619 & 0.600 & 0.636 & 0.664 & 0.635 & 0.662 & 0.664 & 0.686 & 0.725 & 0.748 \\
\hline 460 & 0.100 & 0.176 & 0.209 & 0.283 & 0.372 & 0.412 & 0.426 & 0.463 & 0.482 & 0.537 & 0.604 & 0.616 & 0.602 & 0.647 & 0.652 & 0.643 & 0.659 & 0.667 & 0.690 & 0.723 \\
\hline 480 & 0.094 & 0.164 & 0.205 & 0.267 & 0.352 & 0.409 & 0.424 & 0.452 & 0.472 & 0.510 & 0.572 & 0.620 & 0.600 & 0.617 & 0.652 & 0.639 & 0.656 & 0.664 & 0.669 & 0.693 \\
\hline 500 & 0.090 & 0.150 & 0.204 & 0.252 & 0.330 & 0.401 & 0.424 & 0.442 & 0.473 & 0.497 & 0.541 & 0.603 & 0.622 & 0.601 & 0.626 & 0.649 & 0.630 & 0.655 & 0.666 & 0.668 \\
\hline 520 & 0.084 & 0.138 & 0.204 & 0.239 & 0.310 & 0.390 & 0.425 & 0.436 & 0.466 & 0.480 & 0.517 & 0.574 & 0.621 & 0.607 & 0.603 & 0.633 & 0.636 & 0.643 & 0.664 & 0.665 \\
\hline 540 & 0.080 & 0.128 & 0.202 & 0.228 & 0.296 & 0.374 & 0.422 & 0.434 & 0.456 & 0.480 & 0.503 & 0.545 & 0.602 & 0.624 & 0.599 & 0.614 & 0.638 & 0.638 & 0.649 & 0.661 \\
\hline 560 & 0.077 & 0.123 & 0.197 & 0.220 & 0.283 & 0.354 & 0.416 & 0.434 & 0.449 & 0.479 & 0.488 & 0.523 & 0.576 & 0.623 & 0.615 & 0.592 & 0.620 & 0.635 & 0.639 & 0.657 \\
\hline 580 & 0.074 & 0.117 & 0.189 & 0.218 & 0.269 & 0.335 & 0.405 & 0.435 & 0.445 & 0.470 & 0.485 & 0.513 & 0.549 & 0.603 & 0.620 & 0.600 & 0.594 & 0.619 & 0.622 & 0.641 \\
\hline 600 & 0.071 & 0.111 & 0.177 & 0.219 & 0.258 & 0.320 & 0.393 & 0.434 & 0.442 & 0.461 & 0.486 & 0.493 & 0.529 & 0.576 & 0.620 & 0.617 & 0.595 & 0.604 & 0.623 & 0.627 \\
\hline
\end{tabular}

shear wave velocity are different are represented by the acceleration magnified factors on ground surface (based on the site earthquake of bedrock outcrop) and the distribution of acceleration magnified factors in grounds. Table 2 shows the acceleration magnified factors of the ground on the surface in which soil layer thickness and mean shear wave velocity are different. Influencing of the ground mean shear wave velocity on the distribution of acceleration magnified factors in the ground is shown in Figure 11 when the thickness of ground soil layer is a certain value, and influencing of the ground soil layer thickness on the distribution of acceleration magnified factors in the ground is shown in Figure 12 when the mean shear wave velocity of the ground is a certain value.
As shown in Table 2, the influencing rule of soil layer ground thickness and corresponding mean shear wave velocity on the acceleration response amplitude on ground free surface is complicated, and the influencing rules of soil layer thickness and soil layer mean shear wave velocity on the acceleration response amplitude of ground are coupled. Generally, the acceleration magnified factor on ground surface increases at first and then decreases with the increasing of soil layer shear wave velocity when the soil layer thickness is a fixed value, and the inflection wave velocity value in which acceleration magnified factor on ground surface changed from increasing to decreasing increases with the increasing of soil layer thickness; all these can be represented as yellow labels in Table 2; the acceleration 


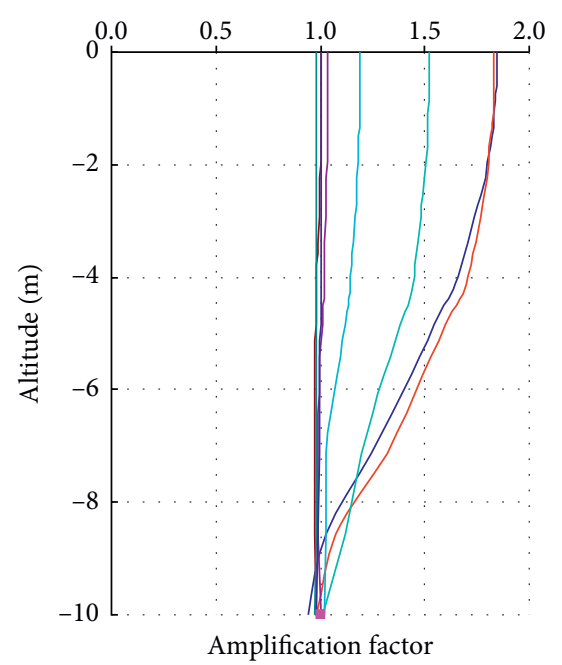

Rock outcrop
Velocity: $212 \mathrm{~m} / \mathrm{s}$
Velocity: $318 \mathrm{~m} / \mathrm{s}$
Velocity: $424 \mathrm{~m} / \mathrm{s}$
Velocity: $530 \mathrm{~m} / \mathrm{s}$
Velocity: $636 \mathrm{~m} / \mathrm{s}$
Velocity: $742 \mathrm{~m} / \mathrm{s}$
Velocity: $848 \mathrm{~m} / \mathrm{s}$
Velocity: $1223 \mathrm{~m} / \mathrm{s}$

(a)

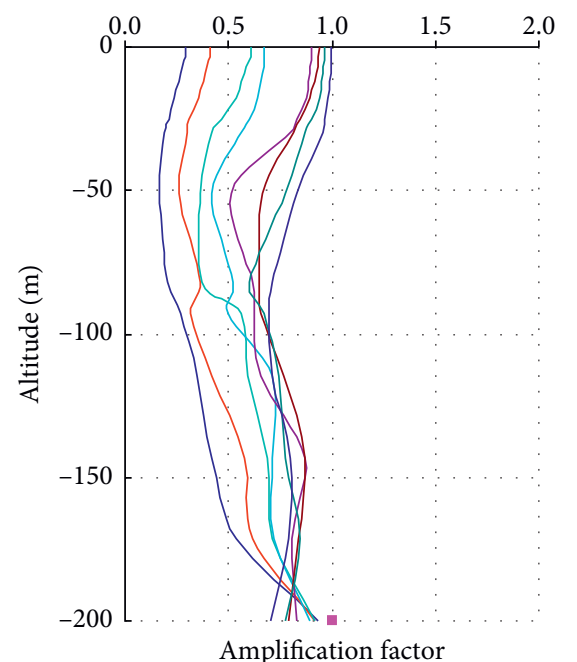

Amplification factor

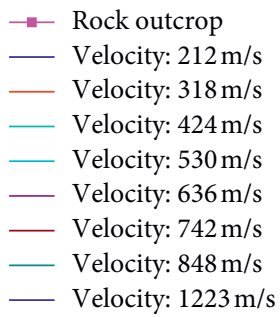

(d)
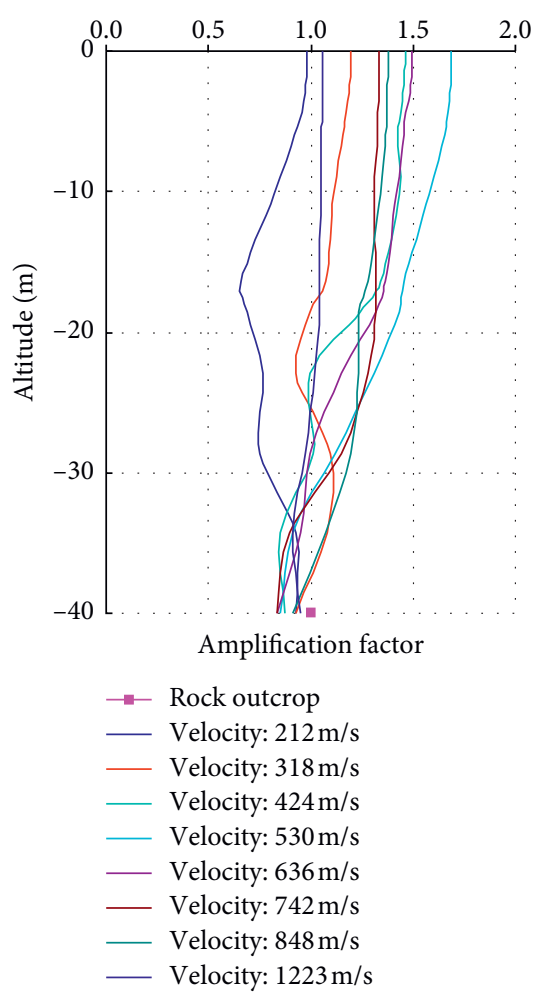

(b)
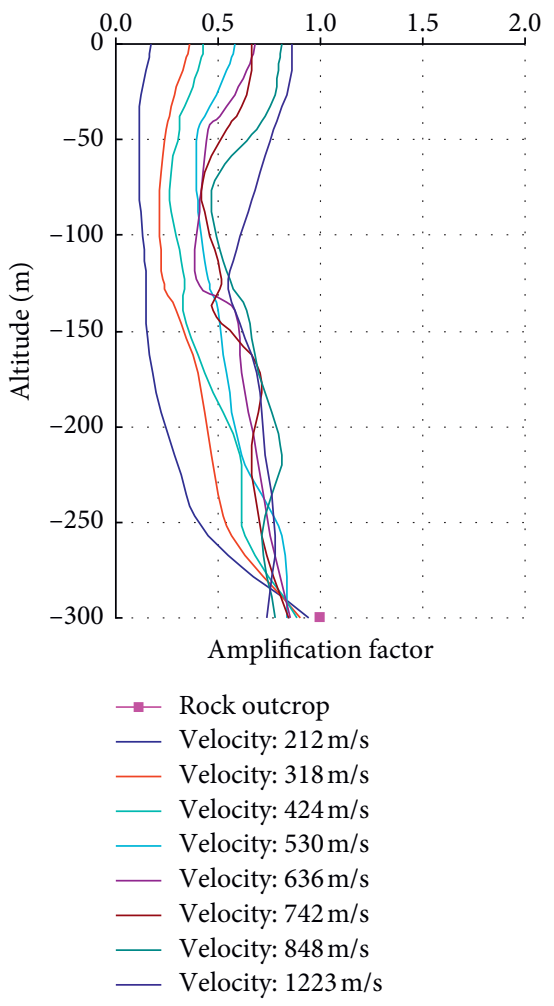

(e)

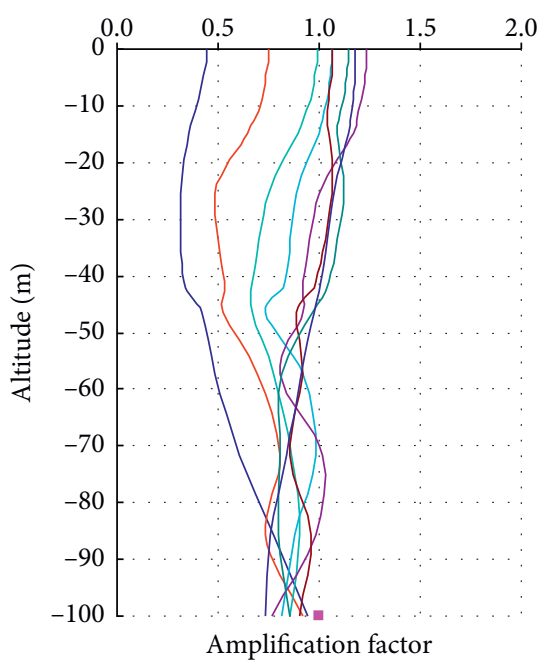

Rock outcrop

Velocity: $212 \mathrm{~m} / \mathrm{s}$

Velocity: $318 \mathrm{~m} / \mathrm{s}$

Velocity: $424 \mathrm{~m} / \mathrm{s}$

Velocity: $530 \mathrm{~m} / \mathrm{s}$

Velocity: $636 \mathrm{~m} / \mathrm{s}$

Velocity: $742 \mathrm{~m} / \mathrm{s}$

Velocity: $848 \mathrm{~m} / \mathrm{s}$

Velocity: $1223 \mathrm{~m} / \mathrm{s}$

(c)

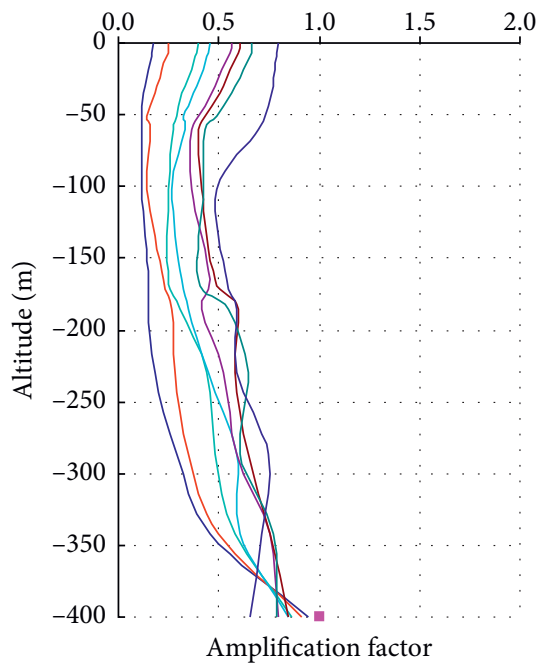

Rock outcrop
— Velocity: $212 \mathrm{~m} / \mathrm{s}$
- Velocity: $318 \mathrm{~m} / \mathrm{s}$
- Velocity: $424 \mathrm{~m} / \mathrm{s}$
- Velocity: $530 \mathrm{~m} / \mathrm{s}$
— Velocity: $636 \mathrm{~m} / \mathrm{s}$
- Velocity: $742 \mathrm{~m} / \mathrm{s}$
- Velocity: $848 \mathrm{~m} / \mathrm{s}$
Velocity: $1223 \mathrm{~m} / \mathrm{s}$

(f)

Figure 11: Continued. 


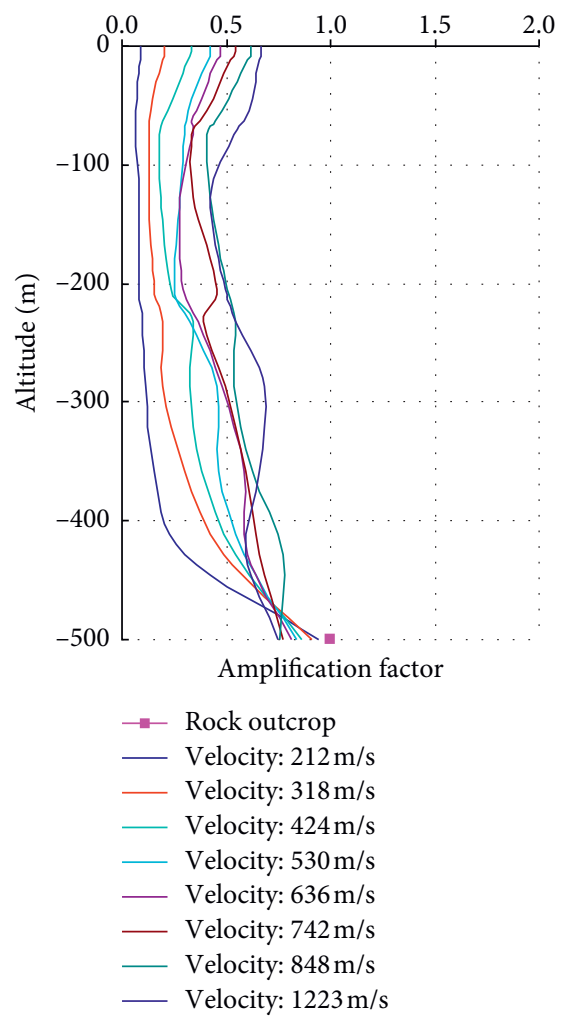

(g)
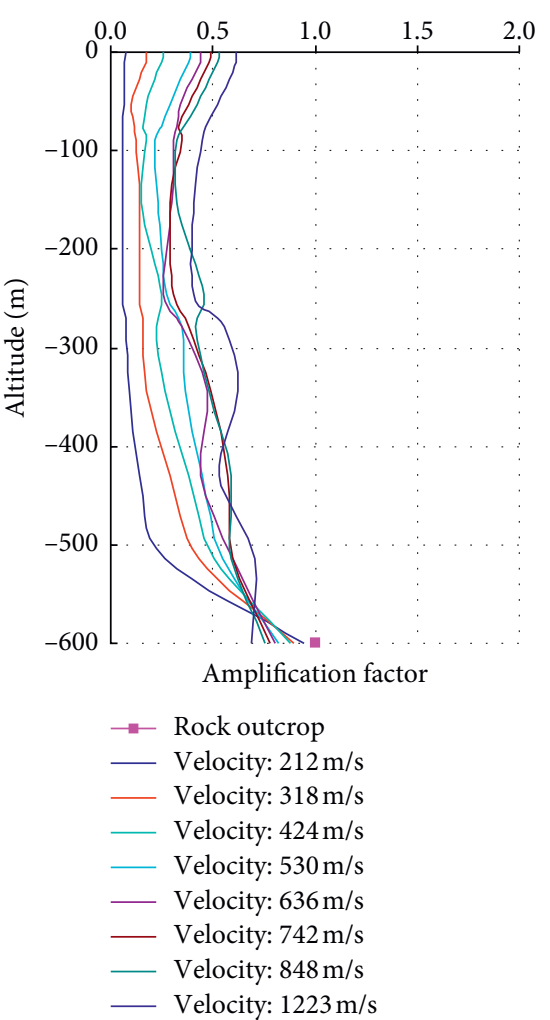

(h)

FIGURE 11: Influence of the ground mean shear wave velocity on the distribution of acceleration magnified factors in the ground when the thickness of ground is certain. (a) $10 \mathrm{~m}$. (b) $40 \mathrm{~m}$. (c) $100 \mathrm{~m}$. (d) $200 \mathrm{~m}$. (e) $300 \mathrm{~m}$. (f) $400 \mathrm{~m}$. (g) $500 \mathrm{~m}$. (h) $600 \mathrm{~m}$.

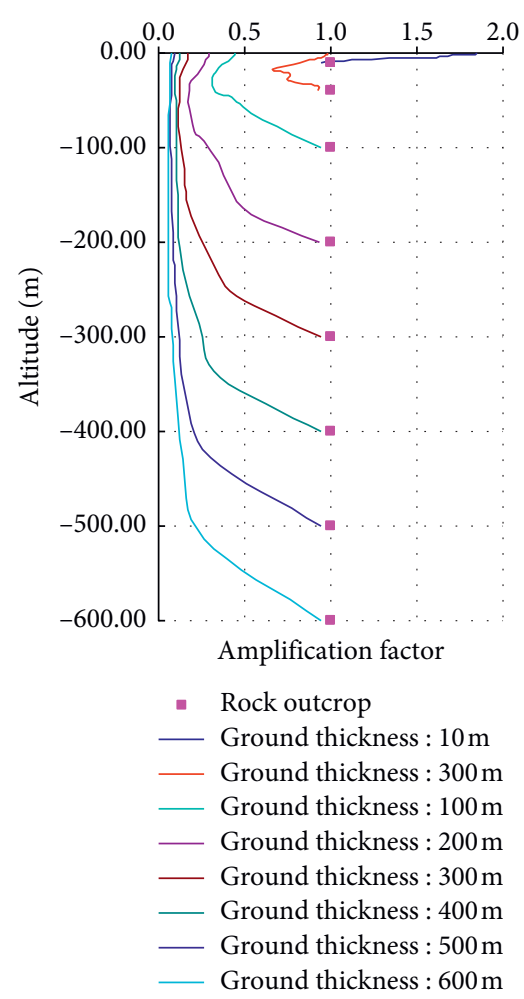

(a)

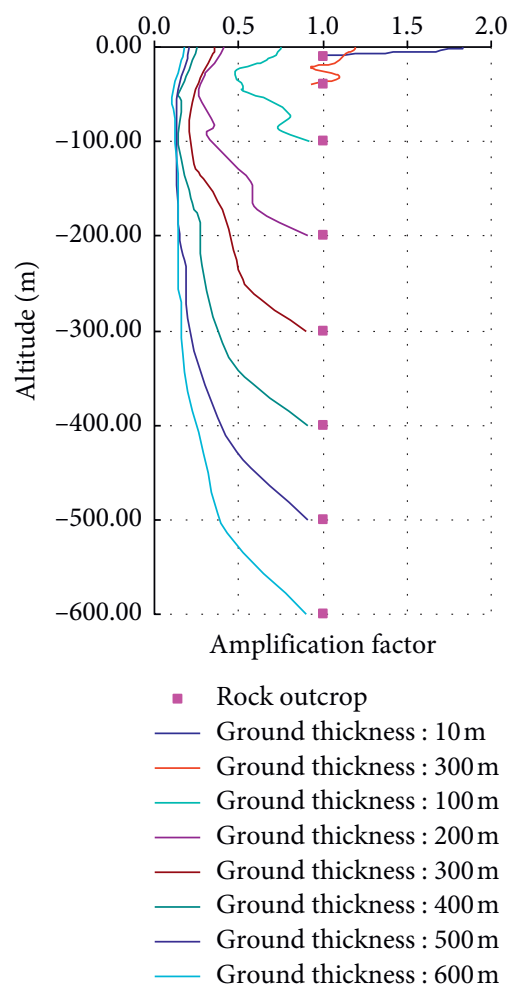

(b)

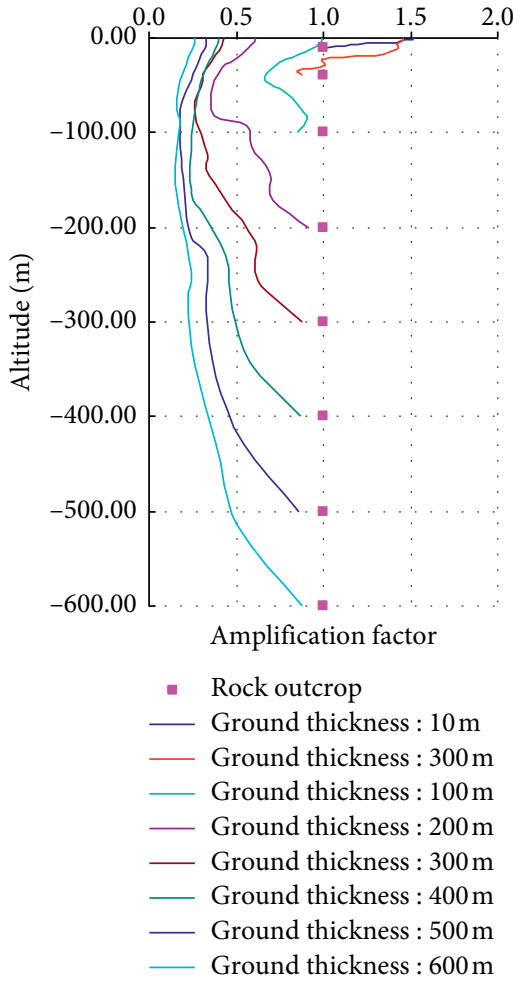

(c)

FIgUre 12: Continued. 


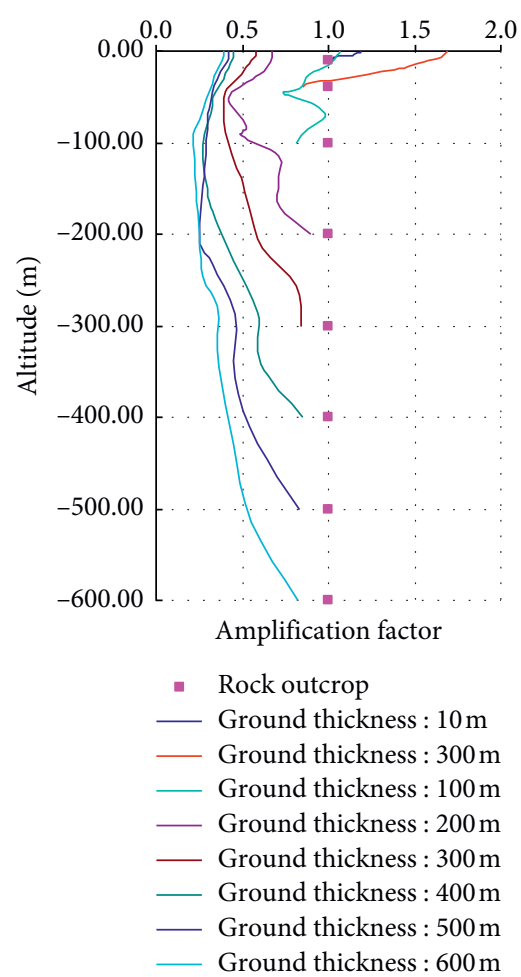

(d)

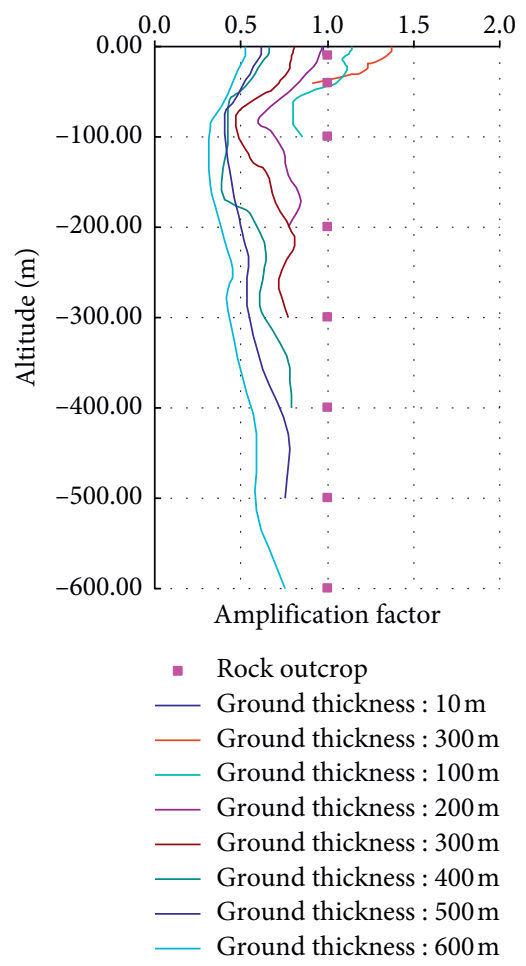

(g)

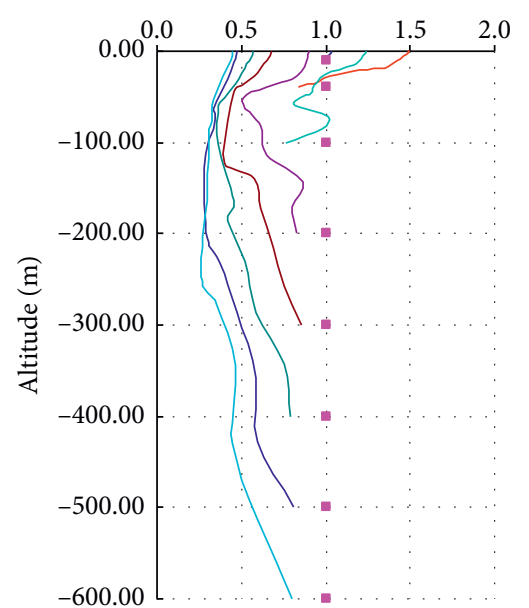

Amplification factor

- Rock outcrop

Ground thickness : $10 \mathrm{~m}$

Ground thickness : $300 \mathrm{~m}$

- Ground thickness : $100 \mathrm{~m}$

_ Ground thickness : $200 \mathrm{~m}$

- Ground thickness : $300 \mathrm{~m}$

- Ground thickness : $400 \mathrm{~m}$

_- Ground thickness : $500 \mathrm{~m}$

__ Ground thickness : $600 \mathrm{~m}$

(e)

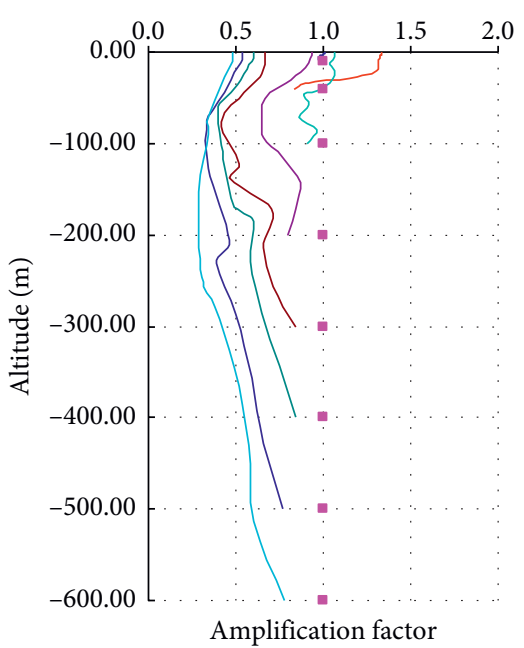

- Rock outcrop

Ground thickness : $10 \mathrm{~m}$

_- Ground thickness : $300 \mathrm{~m}$

- Ground thickness : $100 \mathrm{~m}$

_ Ground thickness : $200 \mathrm{~m}$

__ Ground thickness : $300 \mathrm{~m}$

_ Ground thickness : $400 \mathrm{~m}$

_ Ground thickness : $500 \mathrm{~m}$

_ Ground thickness : $600 \mathrm{~m}$

(f)

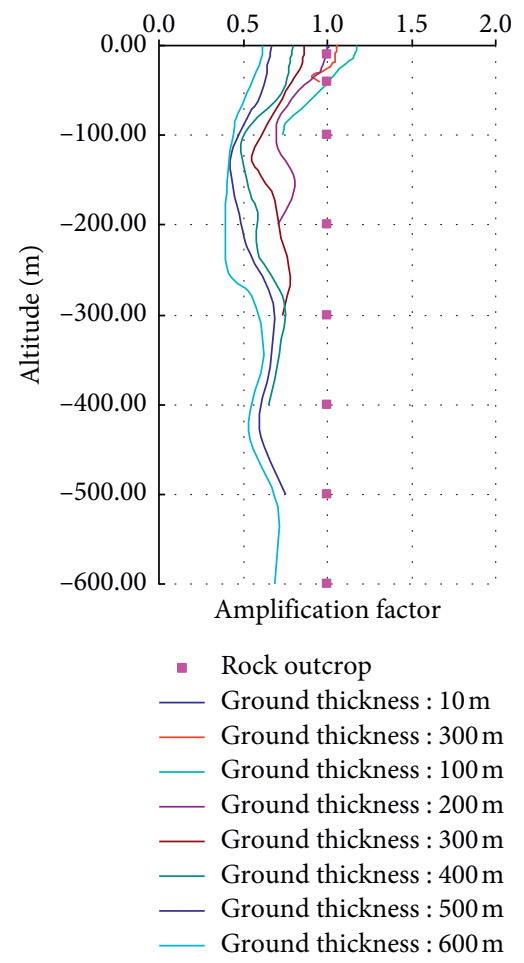

(h)

FIGURE 12: Influence of the ground thickness on the distribution of acceleration magnified factors in the ground when the mean shear wave velocity of the ground is certain. (a) $212 \mathrm{~m} / . \mathrm{s}$. (b) $318 \mathrm{~m} / \mathrm{s}$. (c) $424 \mathrm{~m} / \mathrm{s}$. (d) $530 \mathrm{~m} / \mathrm{s}$. (e) $636 \mathrm{~m} / \mathrm{s}$. (f) $742 \mathrm{~m} / \mathrm{s}$. (g) $848 \mathrm{~m} / \mathrm{s}$. (h) $1223 \mathrm{~m} / \mathrm{s}$.

magnified factor on the ground surface increases at first and then decreases with the increasing of soil layer thickness when the soil layer shear wave velocity is a fixed value, and the inflection thickness value in which acceleration magnified factor on ground surface changed from increasing to decreasing increases with the increasing of soil layer shear 
wave velocity; this rule can be represented as blue labels in Table 2.

The influencing relation that the acceleration response amplitude of overburden layer ground increases at first and then decreases with the increase of ground mean shear wave velocity can be represented clearly by the distribution curves of acceleration magnified factor along the vertical direction in the grounds in which soil layer thicknesses are different as shown in Figure 11.

The acceleration magnified factor increases evenly as the altitude increases when the thickness of the soil layer ground is relatively small. But the influencing relation is different when the thickness of soil layer grounds is relatively large: the acceleration magnified factor decreases at first, then increases with the increase of altitude, and one phenomenon is found in those pictures, the distribution curves of acceleration magnified factors along the vertical direction in the grounds in which thicknesses are large present a state of irregular swinging when the ground mean shear wave velocity is relatively large.

Similarly, the influencing relation that the acceleration response amplitude of overburden layer ground increases at first and then decreases with the increasing of soil layer ground thickness can be represented clearly by the distribution curves of the acceleration magnified factor along the vertical direction in the grounds in which mean shear wave velocities are different, as shown in Figure 12.

In Table 2, (1) when the ground means shear wave velocity changes in the range of $212 \sim 1223 \mathrm{~m} / \mathrm{s}, 1.707$ is the corresponding maximum acceleration magnified factor of ground on the surface in which thickness is a certain value; (2) when the ground thickness changes in the range of $5 \sim 600 \mathrm{~m},{ }_{1846}$ is the corresponding maximum acceleration magnified factor of ground on the surface which means shear wave velocity is a certain value; (3) when the ground thickness changes in the range of $5 \sim 600 \mathrm{~m}, 0985$ is the corresponding inflexion of acceleration magnified factor of ground on the surface in which mean shear wave velocity is a certain value, and the inflexion of acceleration magnified factor is the demarcation point of acceleration response amplification and reduction on the ground surface according to the site earthquake of bedrock outcrop; (4)

1780 is the coincidence point of (1) and (2); (5) 1.040 is the coincidence point of (1) and (3).

For the soil layer grounds in which mean shear wave velocities are relatively small, the seismic motion inputting from bedrock under the ground is magnified by the soil layer ground when the soil layer ground thickness is small relatively, and the seismic motion inputting from bedrock under the ground is reduced by the soil layer ground when the soil layer ground thickness is large relatively. But, for the soil layer grounds in which mean shear wave velocity value exceeds a certain level, the seismic motion inputting from bedrock under the ground is almost invariant along the vertical direction in ground regardless of the size of soil layer thickness, and the seismic motion inputting from bedrock under the ground is not affected obviously by the soil layer ground.

4.3. Coupling Analysis for the Influencing of Ground Thickness and Shear Wave Velocity on the Ground Seismic Motion
Characteristics. Variation rule of the acceleration magnified factors on ground surface with the thickness of ground is shown in Figure 13 when the mean shear wave velocity of ground is different. Figure 14 shows the comparison of the inflection point of the site with different shear wave velocities and the site thickness on the free surface acceleration magnification, including the extreme point of acceleration response and the critical point of magnification and reduction of ground vibration relative to bedrock input ground motion.

Variation rule of the acceleration magnified factors on ground surface with the mean shear wave velocity of ground is shown in Figure 15 when the thickness of ground is different. Comparison of the inflection points which are the mean shear wave velocity value corresponding the maximum value of acceleration magnified factor on ground surface is shown in Figure 16.

As shown in Figures 13 and 14 and Table 2, for the ground which means shear wave velocity is a certain value, the acceleration magnified factor on ground surface increases at first and then decreases with the increase of ground thickness, the corresponding inflection thickness increases with the increasing of ground mean shear wave velocity, and these inflection thickness values are in the range of $10 \sim 100 \mathrm{~m}$. When the ground thickness is over the inflection thickness value, the acceleration magnified factor on the ground surface decreases with the increase of the ground thickness, and it is lesser than 1 when the ground thickness reaches one critical thickness which is the thickness that acceleration response amplitude on the ground surface is magnified or reduced to the inputting seismic motion from bedrock under the ground. The critical thickness of ground increases with the increase of ground mean shear wave velocity, and the maximum value of ground critical thickness is not larger than $240 \mathrm{~m}$. In other words, for the uniform soil layer ground, the acceleration response amplitude on the ground surface will not be larger than the amplitude of seismic motion inputting from bedrock under the ground when thickness of the ground is over $240 \mathrm{~m}$, and the amplifying effects of soil layer ground to the seismic motion inputting from bedrock under the ground is more obvious when the thickness of ground soil layer is in the range of $10 \sim 100 \mathrm{~m}$.

As shown in Figures 15 and 16 and Table 2, for the ground in which soil layer thickness is a certain value, the acceleration magnified factor on ground free surface increases at first and then decreases with the increase of ground mean shear wave velocity, and the acceleration response amplitude is the biggest when the ground mean shear wave velocity is the inflection shear velocity value. The inflection shear velocity value increases with the increase of ground thickness, as shown in Table 2. But, when the ground thickness is over a certain value, the acceleration magnified factor on ground surface increases monotonously with the increasing of ground mean shear wave velocity, and the maximum value of acceleration magnified factor is obtained when the ground mean shear wave velocity is the biggest; abovementioned inflection shear velocity value has no longer existed. As the description mentioned before, the 


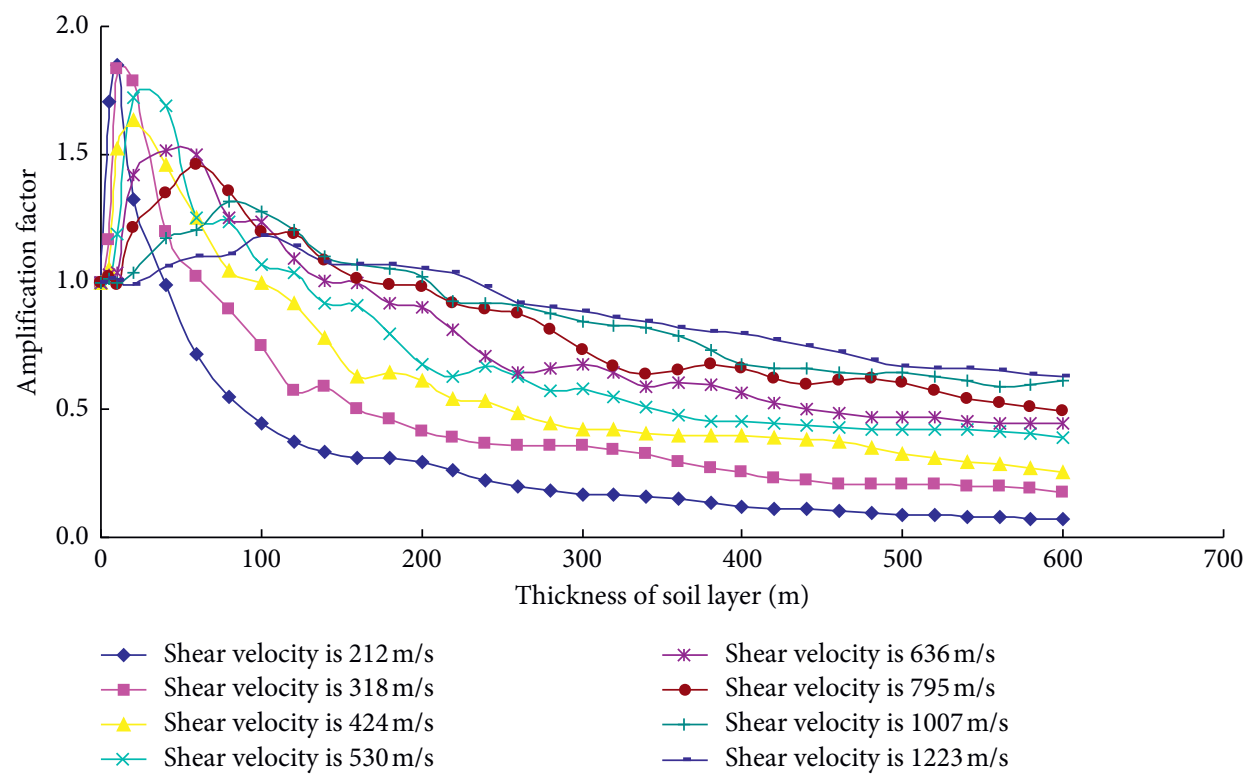

FIGURE 13: Variation rule of the acceleration magnified factors on the ground surface with the thickness of ground when the mean shear wave velocity of the ground is different.

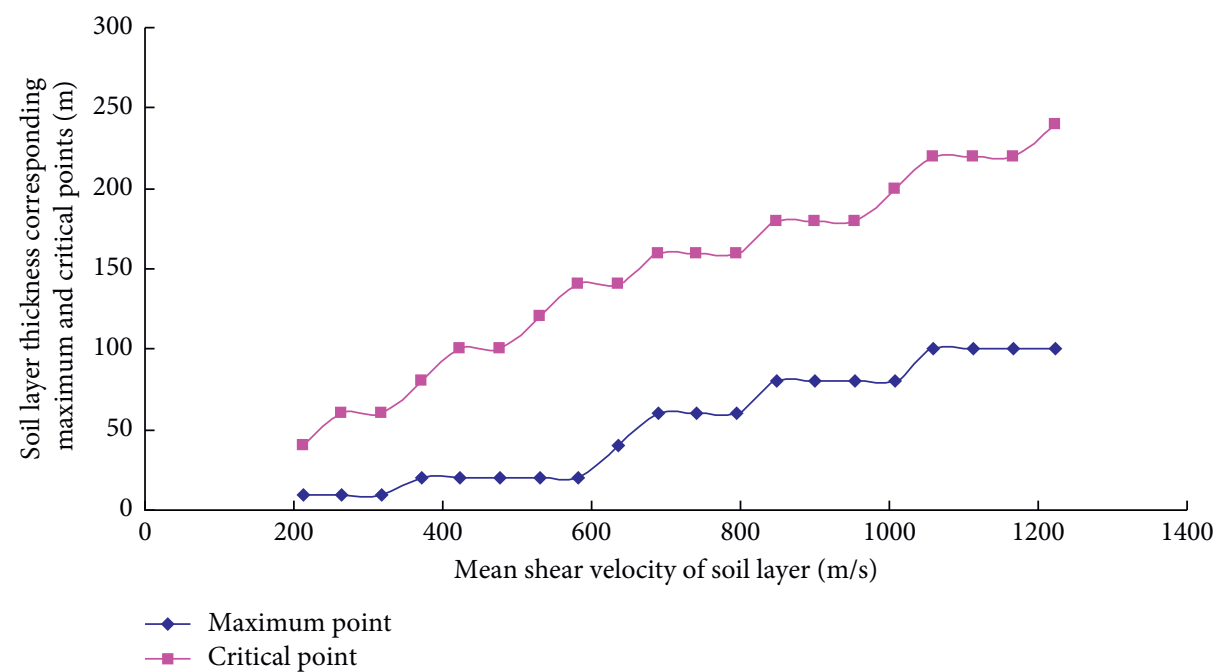

FIGURE 14: Comparision of the ground thickness corresponding the maximum points and critical points of acceleration magnified factor on the ground surface when the mean shear wave velocity of the ground is different.

acceleration response amplitude on the uniform soil ground surface will not be larger than the amplitude of seismic motion inputting from bedrock under the ground when the thickness of ground is over one certain value, and the maximum value of acceleration magnified factor on ground surface should be obtained when the ground mean shear wave velocity is the biggest. When the mean shear wave velocity of ground is big enough that reaches the level of normal bedrock layer; the vibration state on ground surface is as same as the site earthquake on bedrock outcrop.

4.4. Some Discussion on the Abovementioned Analysis Results. All abovementioned analysis and corresponding conclusions are obtained based on the ground seismic response analysis calculation results in which calculation models are the uniform soil layer ground models, some calculation parameters are presumed to be fixed, and the inputting seismic motion is one specific site earthquake. Those factors, such as the calculation model, the calculation parameter, and the inputting seismic motion should have an important effect on the calculation results, such as the above maximum value, critical value, and some specific values of the acceleration magnified factor. But, all these simplifications and assumptions are not against the abovementioned qualitative conclusions which are based on the coupling influencing analysis of soil ground thickness and soil ground mean shear wave velocity on the ground seismic motion characteristics, and it can be verified by the other study results of the authors in [29-31]. 


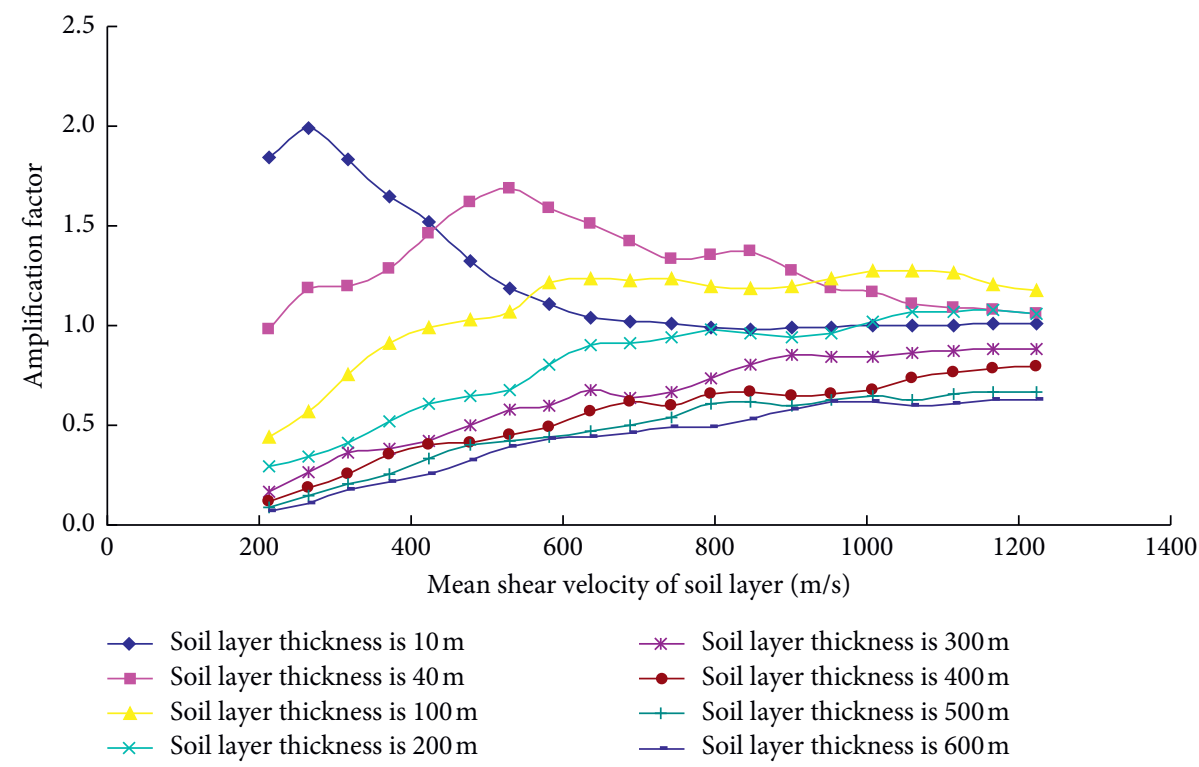

FIGURE 15: Variation rule of the acceleration magnified factors on the ground surface with the mean shear wave velocity of the ground when the thickness of the ground is different.

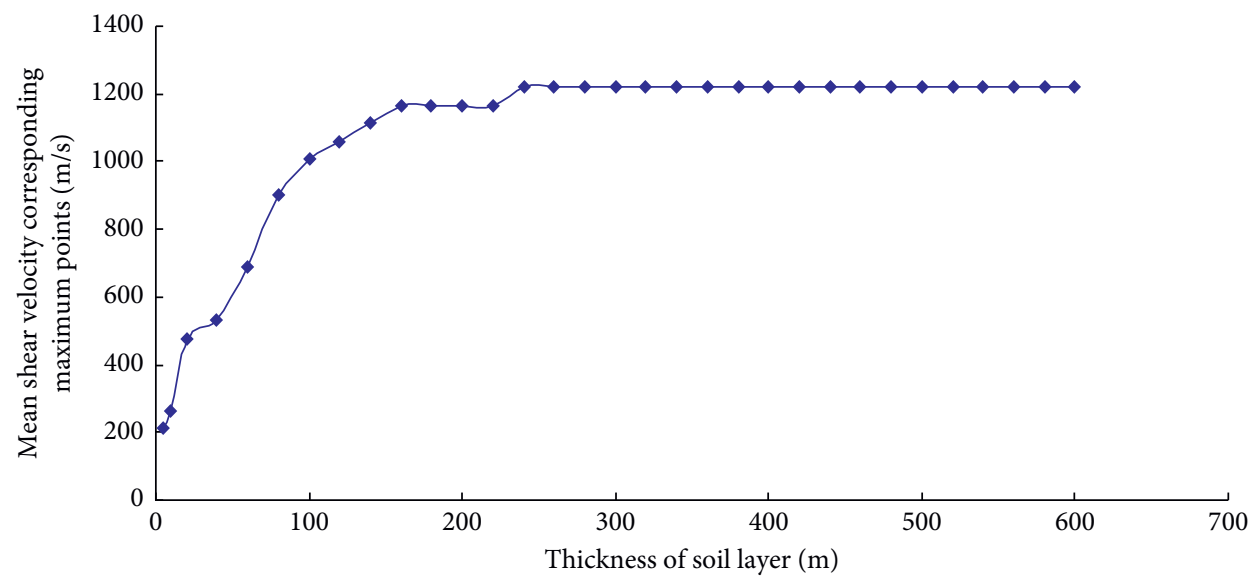

FIGURE 16: Comparision of the ground mean shear wave velocity corresponding the maximum points of acceleration magnified factor on the ground surface when the thickness of the ground is different.

For the dynamic deformation parameters of soil in ground, it produces certain influence on the calculation results that assumes the modulus decay (or damping ratio increasing) characteristic parameters and the maximum damping ratio of soils are not associated with the shear wave velocity (or maximum shear modulus) of soils. The acceleration magnified factor on ground surface and the distribution of acceleration magnified factors in the soil layer ground should be close to the horizontal half-space bedrock layer when the mean shear wave velocity of ground is large enough, that is, the limited ideal state of ground seismic response analysis, considering the influence of ground shear wave velocity. But, because the soil modulus decay (or damping ratio increasing) coefficient $k_{1}$ and the maximum damping ratio $\lambda_{\max }$ have been assumed to be not changeable with the shear wave velocity and the real dynamic characteristic parameters used in calculation are different from the ideal bedrock, the calculation results are different from the ideal state in a certain extent normally. It is not difficult to find that the limited ideal state should exist based on the changing trend of the abovementioned calculation results, and the changing trend of the abovementioned calculation results shows that the calculation results and analysis conclusions should be reliable in this paper.

\section{Conclusion}

Taking a real super-deep overburden layer ground which is the foundation of one earth-rock fill dam in China for example, example analysis for seismic motion characteristics of the super-deep overburden layer ground has been performed in the paper. Influencing rules of the inputting seismic motion characteristics and the seismic motion inputting location on the ground seismic response analysis 
results have been investigated after the basic analysis of ground seismic response characteristics. Furthermore, coupling influencing rules of the ground soil layer thickness and the ground shear wave velocity on the ground seismic motion characteristics have been studied deeply based on the seismic response analysis of ground models in which soil layer thickness and mean shear wave velocity are adjusted in a specific range. The main study conclusions are as follows:

(1) The horizontal layer shearing method for ground seismic response analysis which is based on fluctuation theory can consider the superposition effect of incident wave and reflected wave in the ground and the influence of deep soil layer on the natural vibration characteristics of bedrock surface under the ground; it is applicable for the ground seismic response analysis of horizontally stratified super-deep overburden layer ground.

(2) The seismic response analysis for a super-deep overburden layer which is the foundation of one earth-rock fill dam in China is performed based on the soil dynamic characteristic parameters by field situ testing and soil laboratory testing. Inputting seismic motion of the ground response analysis is the site earthquake which is the vibration progress of the horizontal half-space bedrock layer surface based on the region earthquake hazard analysis. The calculation results of ground seismic response analysis show that the super-deep overburden layer ground has significant reducing effects on the seismic motion inputting from bedrock under the ground, and the long-period components of acceleration response spectra change more prominent on ground surface which is a disadvantage for the antiseismic performance of tower structures.

(3) Seismic motion transmitting characteristics of the super-deep overburden layer ground is influenced by the seismic motion characteristics of inputting earthquake greatly. Magnified effects of the superdeep overburden layer ground on the seismic motion inputting from bedrock reduces with the increasing seismic motion amplitude because of the dynamic deformation nonlinear characteristics of soils. But the magnified effects of super-deep overburden layer ground on the long-period components of inputting seismic motion are enhanced with the increasing of the seismic motion amplitude oppositely.

(4) Results of the ground seismic response analysis for super-deep overburden layer are influenced greatly by the location of seismic motion inputting interface. It will overvalue the magnified effects of overburden soil layer ground on the seismic motion inputting from bedrock greatly, taking the interface of $500 \mathrm{~m} / \mathrm{s}$ shear wave velocity as the seismic motion inputting interface directly.
(5) The acceleration response amplitude of uniform overburden layer ground increases at first and then decreases with the increase of ground shear wave velocity when the ground soil layer thickness is a certain value. There is an inflexion point of ground shear wave velocity that the acceleration response amplitude of the ground is the strongest. But this inflexion point of shear wave velocity does not exist when the ground soil layer thickness is over a certain value, and the acceleration response amplitude of the ground increases monotonously with the increase of ground shear wave velocity.

(6) The influencing rules of ground soil layer thickness and shear wave velocity on the seismic motion characteristics of ground are coupled: the critical ground soil layer thickness of the strongest ground seismic response is influenced by the ground mean shear wave velocity, and also the critical ground shear wave velocity of the strongest ground seismic response is influenced by the ground soil layer thickness.

\section{Data Availability}

The data used to support the findings of this study are included within the article.

\section{Disclosure}

The funding sponsors had no role in the design of the study; in the collection, analyses, or interpretation of data; in the writing of the manuscript; or in the decision to publish the results.

\section{Conflicts of Interest}

The authors declare no conflicts of interest.

\section{Authors' Contributions}

Long Wang wrote the original draft; Zheng-quan Yang reviewed and edited the article; Jian-ming Zhao conceptualized the study and curated the data; Xiao-sheng Liu did formal analysis and developed the methodology; Yan-feng Wen supervised and validated the study.

\section{Acknowledgments}

This work was financially supported by the National Key Research and Development Program of China (2017YFC0404902); the National Natural Science Foundation of China under Grant no. 51509272; the Public Service Sector R\&D Project of Ministry of Water Resource of China (Grant no. 201501035); and the Special Scientific Research Foundation of China Institute of Water Resources and Hydropower Research (GE0145B292017). 


\section{References}

[1] Z.-Q. Yang, Study on Dynamic Analysis Methods Verification Using Shaking Table Model Test and Seismic Motion Input of Earth-Rock Fill Dam, China Institute of Water Resources and Hydropower Research, Beijing, China, 2011.

[2] C.-G. Sun and C.-K. Chung, "Assessment of site effects of a shallow and wide basin using geotechnical information-based spatial characterization," Soil Dynamics and Earthquake Engineering, vol. 28, no. 12, pp. 1028-1044, 2008.

[3] Z.-Q. Yang, X.-S. Liu, X.-G. Wang, and J.-M. Zhao, "An overview on research of ground motion inputting for earthrock fill dam," Journal of China Institute of Water Resources and Hydropower Research, vol. 11, no. 1, pp. 27-33, 2013.

[4] Z.-J. Wang, H.-Y. Liu, T. Meng, and C.-U. Zhou, "Effect of seismic input method on dynamic response of high-panel rockfill dam on deep overburden," Journal of Water Conservancy and Construction Engineering, vol. 18, no. 3, pp. 77-81, 2013.

[5] Y. Ting and L. Shao, "Dynamic characteristics of deep river bed covering dam foundation with soft soil layer," Study Geotechnical Mechanics, vol. 41, no. 1, pp. 267-277, 2020, (in Chinese).

[6] H.-C. Han, Z.-J. Wang, C.-G. Zhou, T. Meng, and Y. Xiang, "Effect of near fault pulse earthquake on dynamic response of high earth-rockfill dam on deep overburden," Water Conservancy and Hydropower Technology, vol. 50, no. 3, pp. 7984, 2013, (in Chinese).

[7] Z.-Q. Yang, X.-S. Liu, J.-M. Zhao, Z.-H. Tian, and Y.-S. Yang, "Analysis of site seismic response considering the structural characteristics of deep overburden," Journal of Hydropower, vol. 34, no. 1, pp. 175-182, 2015, (in Chinese).

[8] D.-Y. Zhu, J.-G. Dong, and Q.-B. Kuang, "Analysis on seismic response of earth-rock dam with deep overburden layer," Northeast Water Conservancy and Hydropower, vol. 29, no. 11, pp. 51-52, 2011, (in Chinese).

[9] X.-N. Wang, X.-T. Zhang, W.-X. Dong, and Y.-Z. Yu, "Analysis of dynamic response to strong shock of core wall rockfill dam with deep," Overburden Journal of Seismic Engineering, vol. 37, no. 2, pp. 349-354, 2015, (in Chinese).

[10] Z.-Q. Yang, Q.-W. Liu, X.-S. Liu, Y.-S. Yang, and N. Chen, "Study on dynamic deformation and strength characteristics of fine soil in super-deep overburden layer by triaxial tests," China Earthquake Engineering Journal, vol. 36, no. 4, pp. 824-831, 2014, (in Chinese).

[11] I. M. Idriss and H. B. Seed, "Seismic response of horizontal soil layers," Journal of the Soil Mechanics and Foundations Division, vol. 94, no. 4, pp. 1003-1031, 1968.

[12] R. Pyke, "Nonlinear soil models for irregular cyclic loadings," Journal of Geotechnical and Geoenvironmental Engineering, ASCE, vol. 106, no. 11, pp. 1277-1288, 1980.

[13] Y. M. A. Hashash and D. Park, "Non-linear one-dimensional seismic ground motion propagation in the Mississippi embayment," Engineering Geology, vol. 62, no. 1-3, pp. 185-206, 2001.

[14] D.-D. Jin, G.-X. Chen, and F.-f. Dong, "Large-scale two-dimensional nonlinear FE analysis on PGA amplification effect with depth and focusing effect of Fuzhou Basin," Journal of Central South University, vol. 21, no. 7, pp. 2894-2903, 2014.

[15] C. Frischknecht and J. J. Wagner, "Seismic soil effect in an embanked deep alpine valley: a numerical investigation of two-dimensional resonance," Bulletin of the Seismological Society of America, vol. 94, no. 1, pp. 171-186, 2004.
[16] Z.-J. Shen, Selected Works on Soil Mechanics of Zhu-Jiang SHEN, Tinghua University Press, Beijing, China, (in Chinese), 2005.

[17] J. Lermo, M. Rodríguez, and S. K. Singh, "The Mexico earthquake of september 19, 1985-natural period of sites in the valley of Mexico from microtremor measurements and strong motion data," Earthquake Spectra, vol. 4, no. 4, pp. 805-814, 1988.

[18] J. Penzien and M. Watabe, "Characteristics of 3-dimensional earthquake ground motions," Earthquake Engineering \& Structural Dynamics, vol. 3, no. 4, pp. 365-373, 1974.

[19] W. B. Joyner, R. E. Warrick, and T. E. Fumal, "The effects of Quaternary alluvium on strong ground motion in the Coyote Lake, California earthquake of 1979," Bulletin of the Seismological Society of America, vol. 71, no. 4, pp. 1333-1349, 1981.

[20] D. M. Boore and W. B. Joyner, "Estimation of ground motion at deep-soil sites in eastern North America," Bulletin of the Seismological Society of America, vol. 81, no. 6, pp. 2167-2185, 1991.

[21] A.-W. Elgamal, M. Zeghal, E. Parra, R. Gunturi, H. T. Tang, and J. C. Stepp, "Identification and modeling of earthquake ground response - I. Site amplification," Soil Dynamics and Earthquake Engineering, vol. 15, no. 8, pp. 499-522, 1996.

[22] E. M. Rathje, A. R. Kottke, and W. L. Trent, "Influence of input motion and site property variabilities on seismic site response analysis," Journal of Geotechnical and Geoenvironmental Engineering, vol. 136, no. 4, pp. 607-619, 2010.

[23] M. K. Koçkar, H. Akgün, and E. M. au, "Evaluation of site conditions for the Ankara Basin of Turkey based on seismic site characterization of near-surface geologic materials," Soil Dynamics and Earthquake Engineering, vol. 30, no. 1-2, pp. 8-20, 2010.

[24] G.-X. Chen and J.-H. Chen, "A study on the influence of seismic wave inputting interface on the earthquake response of deep soft sites," World Earthquake Engineering, vol. 21, no. 2, pp. 36-43, 2005, (in Chinese).

[25] L. A. Wald and J. Mori, "Evaluation of methods for estimating linear site-response amplifications in the los angeles region," Bulletin of the Seismological Society of America, vol. 90, no. 6B, pp. S32-S42, 2000.

[26] S. Castellaro, F. Mulargia, and P. L. Rossi, "Vs30: proxy for seismic amplification?" Seismological Research Letters, vol. 79, no. 4, pp. 540-543, 2008.

[27] C. Architecture and B. Press, "Code for Seismic Design of Buildings (GB 50011-2010),” 2010.

[28] China Water Resource and Hydro-Powder Press, "Specification for Seismic Design of Hydraulic Structures (SL 20397)," 1997.

[29] Z.-Q. Yang, X.-S. Liu, J.-M. Zhao, Z.-H. Tian, and Y.-S. Yang, "Study on ground seismic response analysis considering the structural characteristics of deep overburden layer," Journal of Hydroelectric Engineering, vol. 33, no. 1, pp. 175-182, 2015, (in Chinese).

[30] Z.-Q. Yang, X.-S. Liu, J.-M. Zhao, J.-Q. Zhao, N. Chen, and Q.-W. Liu, "Study on ground seismic response analysis of deep overburden layer," pp. 487-492, 2011.

[31] Z.-Q. Yang, X.-S. Liu, X.-P. Zhou, J.-M. Zhao, and Y.-S. Yang, "Study on ground seismic motion characteristics of deep overburden layer," pp. II487-492, 2013. 